\title{
Engineering Mesophase Stability and Structure via Incorporation of Cyclic Terminal Groups
}

Richard J. Mandle ${ }^{1,2}$, Laurence C. Abbott, ${ }^{1}$ Luma Fritsch, ${ }^{1,3}$ Rachel R. Parker, ${ }^{1}$ Sam Hart, ${ }^{1}$ Adrian C. Whitwood, ${ }^{1}$ Stephen J. Cowling, ${ }^{1}$ John N. Moore, ${ }^{1}$ and John W. Goodby ${ }^{1}$

${ }^{1}$ Department of Chemistry, University of York, York, UK, YO10 5DD

${ }^{2}$ School of Physics and Astronomy, University of Leeds, Leeds, UK, LS2 9JT

${ }^{3}$ Instituto de Química, Universidade Federal do Rio Grande do Sul, Porto Alegre, RS, Brazil

\begin{abstract}
We report on the characterisation of a number of liquid-crystalline materials featuring cyclic terminal groups, which lead to significant enhancements in the temperature range of the mesomorphic state. Materials with only short terminal chains are able to support lamellar mesophase formation by appending a large terminal cyclic unit at the end of a short methylene spacer. X-ray scattering experiments reveal that the layer spacings of the lamellar smectic phase are significantly larger when a cyclic end-group is present than for equivalent linear unsubstituted materials, but there is no effect on orientational order. Fully atomistic molecular dynamics simulations faithfully reproduce experimental layer spacings and orientational order parameters, and indicate that the cyclic terminal units spontaneously segregate into diffuse sub-layers and thus cause the increased layer spacing. This shape segregation predicted by molecular dynamics simulations is observed in the crystalline solid state by $\mathrm{X}$-ray diffraction.
\end{abstract}

\section{Introduction}

Liquid crystals for display applications typically comprise a rigid 'core' unit flanked with a terminal chain and a polar terminal group. The need to engineer the properties of nematic liquid-crystals has led to an understanding of how changes to molecular structure impact the bulk properties of these materials. Positioning a bulky group at the end of the terminal chain can lead to reductions in melting points with only minimal change in the clearing point; ${ }^{1-7}$ electron-withdrawing end groups $\left(-\mathrm{Cl},-\mathrm{Br},-\mathrm{Ar} F_{\mathrm{n}}\right)$ can suppress the $\mathrm{SmA}$ mesophase of cyanobiphenyl derived $\mathrm{LCs}^{8}$ although in phenylpyrimidine-derived materials these halogen terminated end groups can actually stabilise the SmA state. ${ }^{9}$ Apolar or weakly polar bulky terminal groups $\left(-\mathrm{C}\left(\mathrm{CH}_{3}\right)_{3}\right.$ etc.) suppress the nematic phase and lead to smectogenic materials, albeit with reductions in the clearing point relative to the parent material. ${ }^{4,5}$ The smectic layer spacing of materials incorporating apolar bulky terminal groups is inversely dependent on temperature. ${ }^{5}$

Some archaea incorporate cyclic units in their lipids ${ }^{10}$ which confers, inter alia, the ability to withstand greater extremes of temperature than eukaryotes 11 by either raising the temperature at which the liquid crystalline lipid-bilayers undergo isotropisation, ${ }^{12,13}$ or lowering the temperature at which they undergo crystallisation. ${ }^{14,15}$ Inspired by this, we considered that incorporating cyclic units into the terminal regions of liquid crystalline materials could perhaps offer a similar thermal advantage. Cyclic end groups have previously been studied in the context of the tilted smectic $C$ phase for use in display devices, ${ }^{16,17}$ but not for nematic or 
SmA type materials (Figure 1) which is the focus of this present article. Furthermore, in prior examples ${ }^{16,17}$ the bulky cyclic group is attached to the terminal chain via polar groups (esters, ethers), and thus it is difficult to determine to what extent steric and electronic effects are responsible for the resulting behaviour.

Using the 4-cyanobiphenyl mesogenic core unit, in this work we have studied different combinations of ring size, alkyl chain length and linking-unit and their impact on the mesomorphic behaviour of the resulting materials. In all cases the cyclic group was directly attached to the alkyl chain and can be described as non-polar; we can therefore attribute any changes in behaviour solely to steric factors. Some cyclic terminal groups were found to give significant enhancements to the transition temperatures relative to the linear unsubstituted parent compounds, to induce smectic phases for relatively short terminal chain lengths, as well as leading to anomalously large smectic layer spacings and strong odd-even effects.
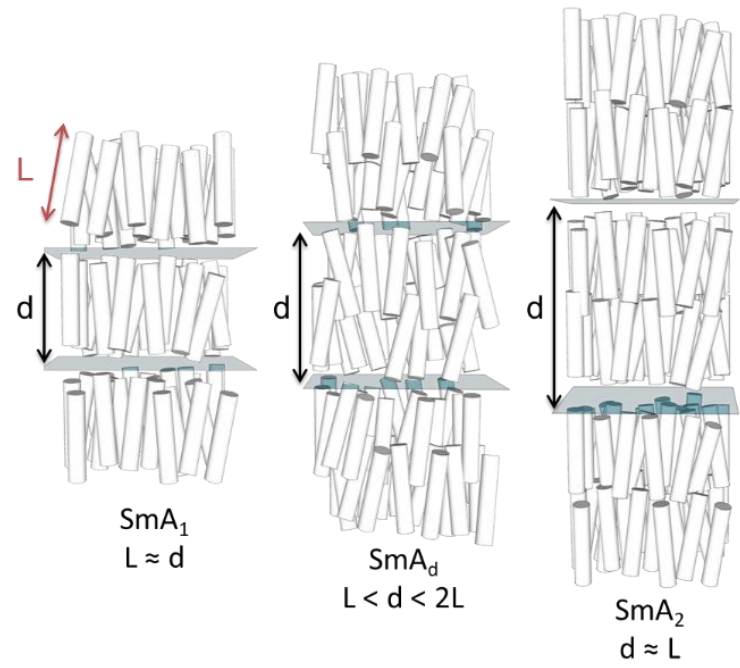

Figure 1: Cartoon depictions of the sub types of the smectic $A$ phase: monolayer $\left(\mathrm{SmA} \mathrm{A}_{1}\right)$, interdigitated $\left(S m A_{d}\right)$ and bilayer $\left(S m A_{2}\right)$. The molecules are indicated as cylinders with an aspect ratio of 10 , the molecular length $(\mathrm{L})$ and layer spacing (d) are indicated. The layers are shown as transparent planes, however in reality they are diffuse and disordered rather than being well defined.

\section{Experimental}

Compound 1 was prepared via the Simmons-Smith cyclopropanation of 4-(pent-4-eneyloxy)4'-cyanobiphenyl. Compound 2 was obtained via the metallophotoredox C-C coupling ${ }^{18}$ of 4(3-bromopropoxy)-4'-cyanobiphenyl with cyclobutanecarboxylic acid. Compounds $\mathbf{3}-\mathbf{5}$ were prepared via Mitsunobu coupling of 4-hydroxy-4'-cyanobiphenyl with an appropriate cycloalkyl-terminated alcohol; 3-cyclopentylpropan-1-ol and 3-cyclohexylpropan-1-ol were sourced commercially and used to synthesise $\mathbf{3}$ and $\mathbf{4}$, respectively. For $\mathbf{5}$, alkyl-alkyl cross coupling ${ }^{19}$ of the redox active $\mathrm{N}$-hydroxyphthalamide ester of cycloheptanoic acid with (3ethoxy-3-oxypropyl)zinc bromide, followed by reduction with $\mathrm{LAH}$, to afford 3cycloheptylpropan-1-ol. The structures of compounds $\mathbf{1 - 5}$ were confirmed by single crystal $X$-ray diffraction and are show in Scheme 1 as thermal ellipsoid models (50\% probability). Single crystal $\mathrm{x}$-ray diffraction data were collected at $110 \mathrm{~K}$ on an Oxford Diffraction 
SuperNova diffractometer with Cu-K $\mathrm{K}_{\alpha}$ radiation $\left(\lambda=1.54184 \AA^{\prime}\right.$ using an EOS CCD camera; further information is given in the ESI to this article.

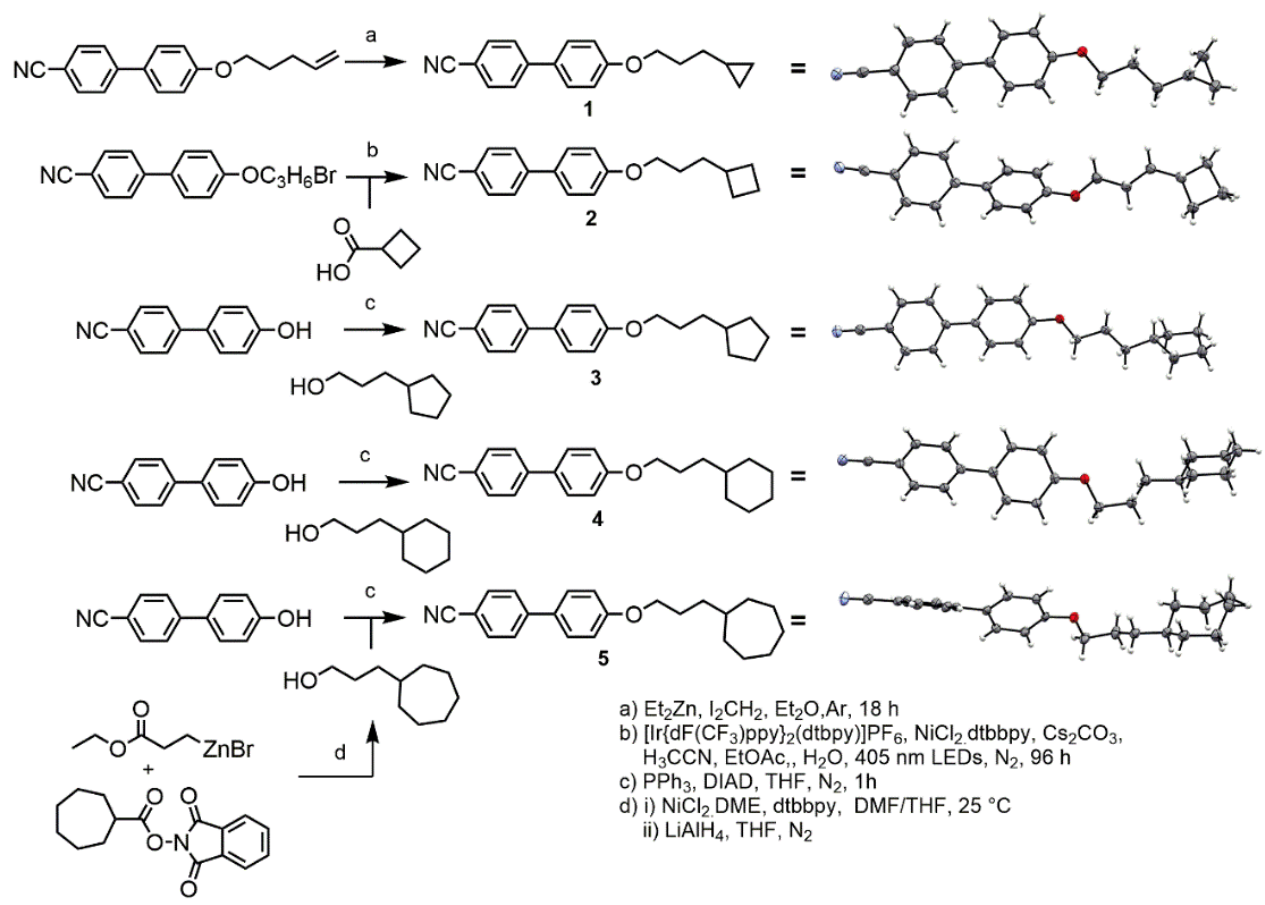

Scheme 1

Compounds 6 - 10 (Scheme 2) were prepared via Mitsunobu coupling of 4-hydroxy-4'cyanobiphenyl with an appropriate cyclohexyl-terminated alcohol; these were sourced commercially with the exceptions of cyclohexylpentan-1-ol (prepared according to ref ${ }^{20}$ ) and 6-cyclohexylhexan-1-ol (prepared according ref ${ }^{21}$ ). Compound 11 (Scheme 2) was prepared via esterification of commercially available 5-cyclohexylpentanoic acid with 4-hydroxy-4'cyanobiphenyl using EDC/DMAP. Full synthetic details for all transformations are given in the ESI.

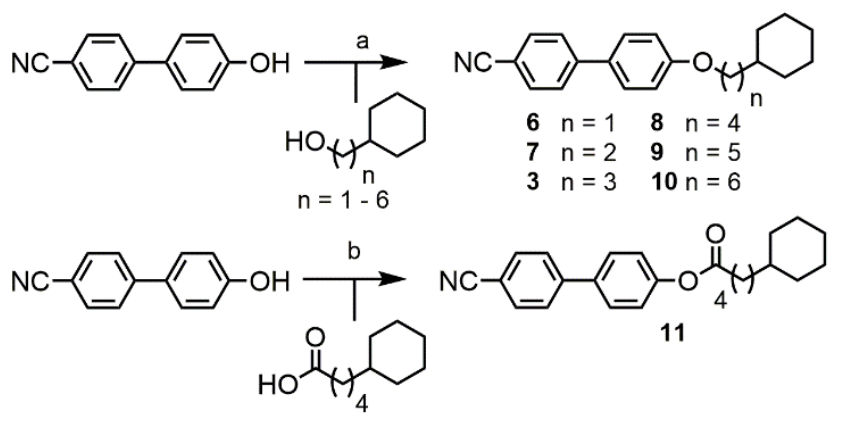

a) $\mathrm{PPh}_{3}, \mathrm{DIAD}, \mathrm{THF}, \mathrm{N}_{2}, 1 \mathrm{~h}$

b) EDC. $\mathrm{HCl}, \mathrm{DMAP}, \mathrm{DCM}$

\section{Scheme 2}


Transition temperatures were determined by polarised optical microscopy (POM, photomicrographs in ESI) and differential scanning calorimetry (DSC) with additional small angle X-ray scattering (SAXS) studies on selected compounds. Numerical integration of Xray scattering data was performed in Matlab. Electronic structure calculations were performed in Gaussian G09 rev E01, ${ }^{22}$ individual conformers were aligned using the VMD software package ${ }^{23}$ and rendered using Qutemol. ${ }^{24}$ Details of the molecular dynamics (MD) simulation methods are given in the ESI.

\section{Results}

The transition temperatures and associated enthalpies of transition of $\mathbf{1 - 5}$, in which the spacer is held at three methylene units while the size of the terminal ring is varied, are presented along with the analogous linear material $(50 \mathrm{CB})$ in table 1.

Whereas compounds 1 and 2 exhibit reductions in clearing points relative to 5OCB we observe that materials with larger cyclic end groups (3 - 5) exhibit clearing points notably higher than those of 5OCB. The clearing points correlate with the ring strain of the cyclic end-group; cyclopropane has the lowest clearing point and highest ring strain, whereas cyclohexane has the highest clearing point and lowest ring strain. This enhancement in clearing point is accompanied by an increase in melting point - compounds $\mathbf{1}-\mathbf{5}$ exhibit higher melting points than the linear parent (5OCB). All five novel materials exhibit nematic phases; however it is surprising to observe a smectic A phase in $\mathbf{5}$ given the short terminal chain employed. The end-to-end length of all-trans 5 is only slightly larger than 5OCB (18.8 $\AA$ versus $17.0 \AA$, both at the B3LYP/6-31G(d,p) level of DFT). The layer spacing of the SmA phase of $\mathbf{5}$ was measured to be $31.0 \AA$ and temperature independent when studied by SAXS. The $\mathrm{d} / \mathrm{I}$ ratio (layer spacing over all-trans molecular length) is therefore 1.65 for $\mathbf{5}$, this being significantly larger than would be expected for a material with a linear alkoxy chain; for example 8OCB (4-octyloxy-4'-cyanobiphenyl) has a d/I ratio of 1.43. ${ }^{25}$ The SmA phase of 5 is therefore interdigitated and thus of the subtype ' $S m A_{d}$ ', This interdigitation is common for cyanobiphenyls and results from having molecules form dynamic antiparallel associated pairs through dipole-dipole interactions. ${ }^{26}$ 


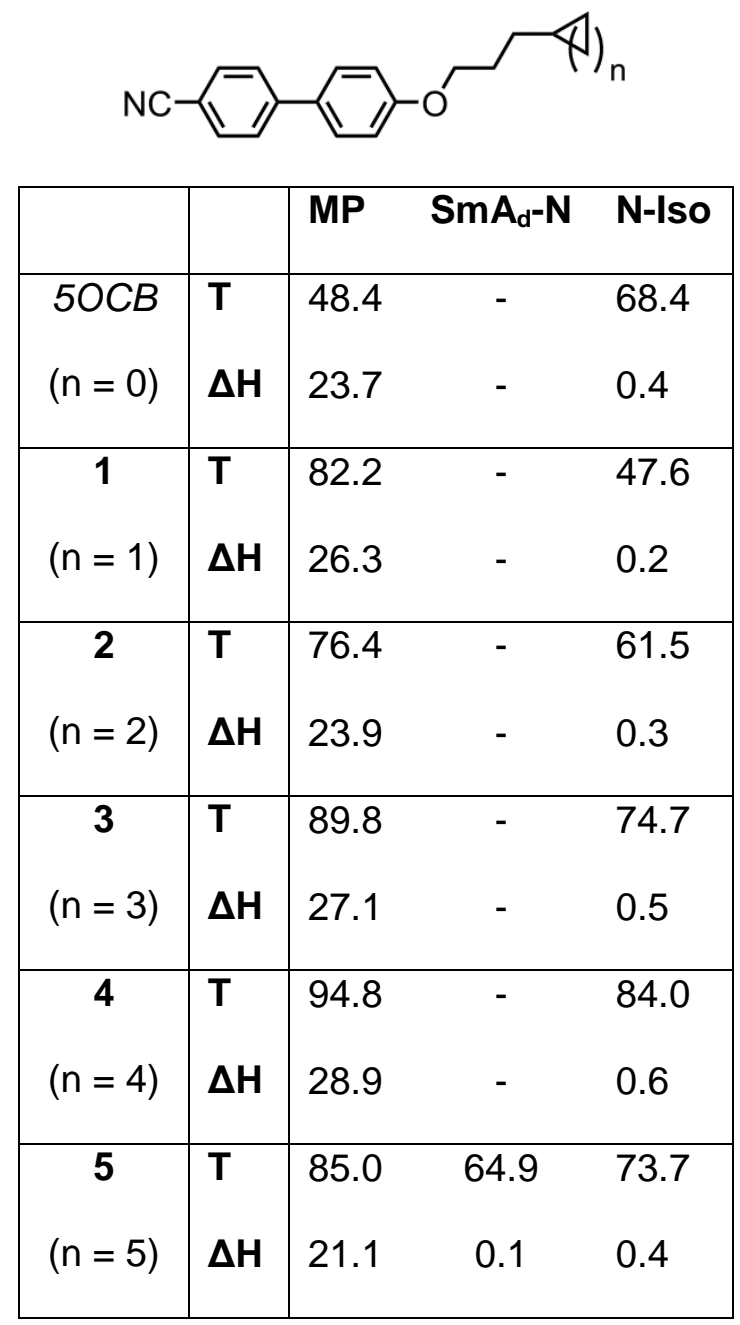

Table 1: $\quad$ The transition temperatures $\left(\mathrm{T},{ }^{\circ} \mathrm{C}\right)$ and associated enthalpies $\left(\Delta \mathrm{H}, \mathrm{kJ} \mathrm{mol}^{-1}\right)$ of compounds $\mathbf{1}-\mathbf{5}$, as determined by DSC at a heat/cool rate of $10^{\circ} \mathrm{C} \mathrm{min}^{-1}$ : Values of $50 \mathrm{OCB}$ are given for comparison, and were determined by the same method using the same instrument.

The constituent molecules of the antiparallel cyanobiphenyl pairs rotate about their long axis in the SmA phase - both independently and cooperatively $-{ }^{27}$ meaning that the time averaged shape of the individual molecules is rod like. To estimate the gross shape of $\mathbf{4}$ and $\mathbf{5}$ we obtained optimized geometries at the B3LYP/6-31G(d) level of DFT for both materials before optimizing the geometries of conformers that arise from ring flips or twist-boat states. Geometries not within $20 \mathrm{~kJ} \mathrm{~mol}^{-1}$ of the global minima were discarded, and those within this limit were overlaid (Figure $2 a$ for 4 and $2 b$ for 5 ). This gives a more realistic picture of the likely gross shape of the terminal group than afforded by a single conformer, and the volume occupied by the terminal group is larger than that of the biphenyl core unit; hence, the molecules are more conical than rod like (Figure $2 b$ ). The layer spacing of $\mathbf{5}$ is significantly larger than materials with linear terminal chains; we propose that the steric bulk of the cyclic group suppresses the interpenetration of the terminal alkyl chains into adjacent layers and leads to the enhanced layer spacing (Figure 2c, 2d). The observed increases in transition temperatures in compounds $\mathbf{1} \mathbf{- 5}$ can be considered as resulting from the better filling of free volume by materials with bulky end groups than linear chains due to the conical, rather than 
rod-like, shape. ${ }^{28,29}$ Indeed, in the crystalline state (Figure $2 e$ ) the bulky cyclic groups of $\mathbf{5}$ are clearly segregated from the 4-cyanobiphenyl regions, giving alternating planes of aromatic and alicyclic regions. The XRD crystal structure of compounds 1, 2 and 4 exhibit similar segregation into cycloalkyl rich planes and biphenyl rich planes (Figure SI-8, SI-9 SI-11 in ESI) This segregation is also present for $\mathbf{3}$, albeit less pronounced than for compounds $\mathbf{2 , 4}$ and $\mathbf{5}$ (Figure $\mathrm{SI}-10$ in ESI).

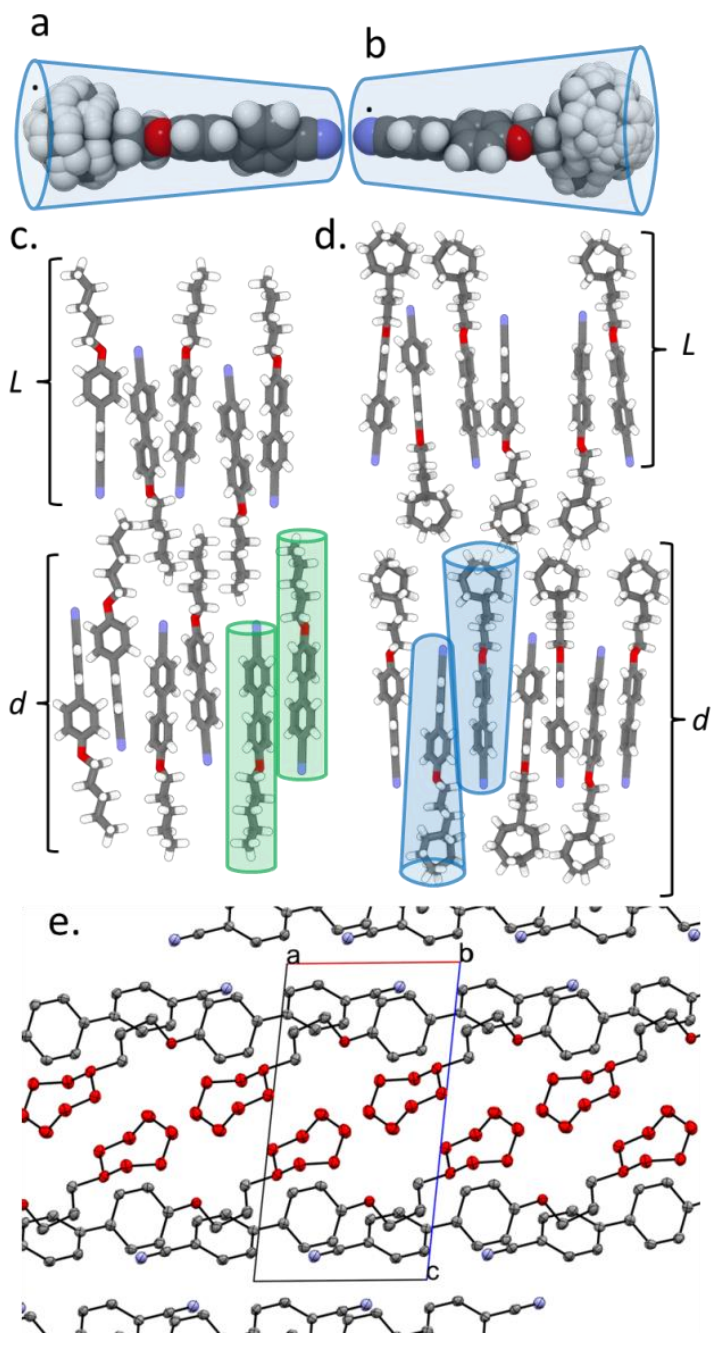

Figure 2: $\quad$ Overlaid geometries (DFT; B3LYP/6-31G(d)) of conformers within $20 \mathrm{~kJ} \mathrm{~mol}^{-1}$ of the ground state for (a) compound 4 and (b) compound 5 obtained by allowing ring flips and twist-boat forms but keeping the methylene chain and biphenyl rigid. Depiction of the $\mathrm{SmA}_{d}$ phase exhibited by (c) a linear alkoxycyanobiphenyl, (d) a cyanobiphenyl with a terminal group (compound 5). Rod-like (c) and conical (d) molecular shapes are indicated. (e) Packing in the solid state of $\mathbf{5}$ as determined by single crystal XRD; $a, b$ and $c$ refer to the axes of the unit cell $(P \overline{1})$, hydrogen atoms are excluded and the carbon atoms of the cycloheptyl ring are coloured red, both for clarity. 
We next studied the effect of the length of the methylene spacer between the cyanobiphenyl 'core' and the cyclic end-group upon the liquid crystalline properties (Table 2). We employed a cyclohexyl terminal group as this not only gave the highest clearing points (Table 1), simplifying study of smectic phases by SAXS, but also has zero ring strain.

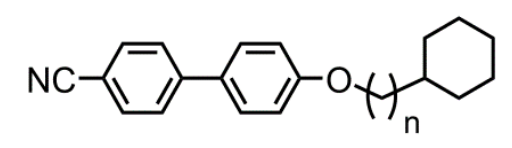

\begin{tabular}{|c|l|ccc|}
\hline & & MP & $\mathbf{S m A}_{\mathbf{d}}-\mathbf{N}$ & $\mathbf{N}-\mathbf{l s o}$ \\
\hline $\mathbf{6}$ & $\mathbf{T}$ & 120.8 & - & - \\
$(\mathrm{n}=1)$ & $\boldsymbol{\Delta} \mathbf{H}$ & 33.7 & - & - \\
\hline $\mathbf{7}$ & $\mathbf{T}$ & 89.7 & - & - \\
\hline $\mathbf{4}$ & $\mathbf{\Delta H}$ & 27.4 & - & - \\
$(\mathrm{n}=3)$ & $\mathbf{\Delta H}$ & 28.9 & - & 0.6 \\
\hline $\mathbf{8}$ & $\mathbf{T}$ & 80.1 & 51.8 & 54.6 \\
$(\mathrm{n}=4)$ & $\mathbf{\Delta H}$ & 34.6 & 0.4 & 0.4 \\
\hline $\mathbf{9}$ & $\mathbf{T}$ & 97.8 & 82.7 & 85.3 \\
$(\mathrm{n}=5)$ & $\mathbf{\Delta H}$ & 34.1 & 2.2 & 0.6 \\
\hline $\mathbf{1 0}$ & $\mathbf{T}$ & 76.4 & 66.8 & - \\
$(\mathrm{n}=6)$ & $\mathbf{\Delta H}$ & 25.0 & 2.2 & - \\
\hline
\end{tabular}

Table 2: $\quad$ Transition temperatures $\left(\mathrm{T},{ }^{\circ} \mathrm{C}\right)$ and associated enthalpies of transition $(\Delta \mathrm{H}$, $\mathrm{kJ} \mathrm{mol}^{-1}$ ) of cyclohexyl-terminated nOCB compounds.

Compounds 6 and 7 are non-mesogenic due to the short spacer between the end group and the core unit. Unlike 4, which exhibits only a nematic phase, 8 and 9 both exhibit nematic and SmA phases. The enthalpy (and therefore entropy) associated with the $\mathrm{N}-\mathrm{Sm} \mathrm{A}_{d}$ transition is much larger for $\mathbf{9}$ than $\mathbf{8}$ and we will return to this point shortly. Compound $\mathbf{1 0}$ exhibits a direct Iso-SmA transition. All three phase transitions in Table 2 display a strong odd-even effect; transition temperatures are notably higher for odd parity materials. The smectic layer spacing of 9 was determined by SAXS, and presented as a d/I ratio using calculated molecular lengths (B3LYP/6-31G(d) level, 21.2 $\AA$ ) as a function of reduced temperature in Figure 3a. We also measured the layer spacings of two comparator materials, these were selected as they have approximately the same molecular length as compound $9-80 C B(L=21.8 \AA)$ and 2Si4OCB $(L=21.9 \AA)$ - data are presented in Figure 3 a along with molecular structures (Figure $3 d, 3 e$ ) 

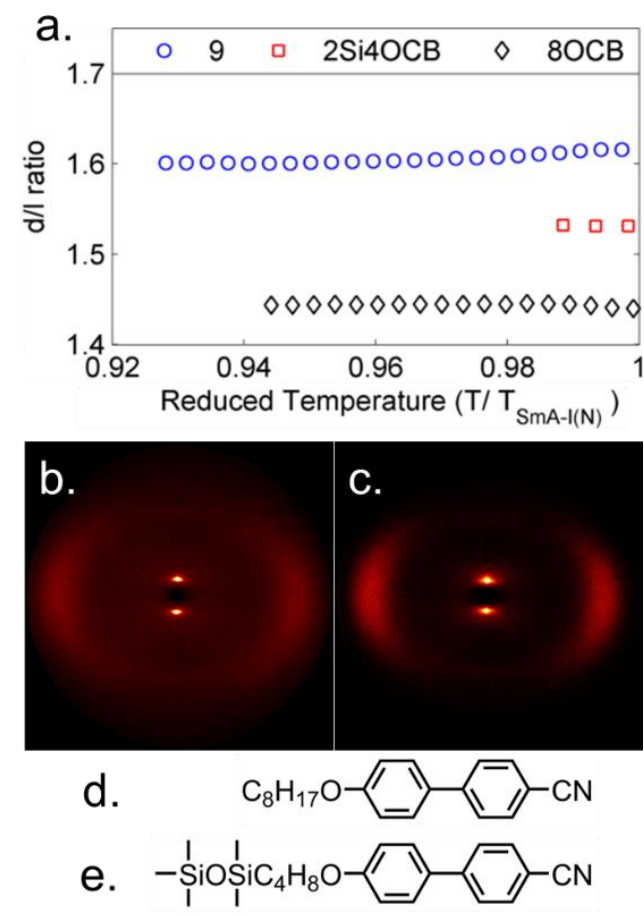

Figure 3: (a) Plot of the $d / /$ ratio of 9,2 Si4OCB and $8 O C B$ as a function of reduced temperature. Two dimensional SAXS patterns for magnetically aligned samples of compounds 8 (b) and $\mathbf{9}$ (c) at a reduced temperature (T / T TmA-N) of 0.98. The molecular structures of 8OCB (Cr $54.5 \mathrm{SmA} 67.2 \mathrm{~N} 80.0 \mathrm{lso}$ ) and 2Si4OCB (Cr 39.7 SmA 29.1 Iso) are given in (d) and (e), respectively.

Typically the layer spacing of the $S m A_{d}$ phase is almost invariant with temperature, ${ }^{26}$ however some materials with an acyclic 'bulky' group display temperature dependent layer spacing in the $\mathrm{SmA}_{d}$ phase. ${ }^{5}$ In the present study we observe the layer spacing of 9 to vary only slightly with temperature, however the $\mathrm{d} / \mathrm{l}$ ratio is far larger than that of $80 \mathrm{CB}$ (1.60 vs 1.43 , respectively). The siloxane terminated material 2 Si4OCB ${ }^{30}$ exhibits a short range smectic $A$ phase whose $\mathrm{d} / \mathrm{l}$ ratio is intermediate between 9 and $80 \mathrm{CB}$. Study of compounds $\mathbf{8}$ and 10 by SAXS was complicated by crystallisation, however we were able to collect a single SAXS frame at a temperatures of $44^{\circ} \mathrm{C}$ and $65^{\circ} \mathrm{C}$, respectively. For 8 and 10 we measure layer spacings of $31.7 \AA$ and $35.4 \AA$, respectively; this corresponds to $d / /$ ratios of 1.61 for both materials. Of the materials studied by $\operatorname{SAXS}(\mathbf{5}, \mathbf{8}, \mathbf{9}, \mathbf{1 0})$ we find the $\mathrm{d} / \mathrm{l}$ ratios to be effectively identical.

It is known that cyanobiphenyl leads to antiparallel pairing through dipole-dipole interactions, increasing the effective length-to-breadth ratio (i.e. aspect ratio) and leading to interdigitated smectic phases. ${ }^{25,26}$ To determine if this is a steric effect we devised compound 11, a structural homologue of 9 however with an increased dipole moment (at the DFT(B3LYP/631G(d)) level: $\mathbf{9}=7.2$ Debye, $\mathbf{1 1}=7.6$ Debye) that might be expected to alter the degree of antiparallel pairing and so lead to a change in layer spacing. If the effect is purely steric then the layer spacings should be unchanged. The transition temperatures and associated enthalpies of transition of $\mathbf{9}$ and $\mathbf{1 1}$ are given in Table 3 . 


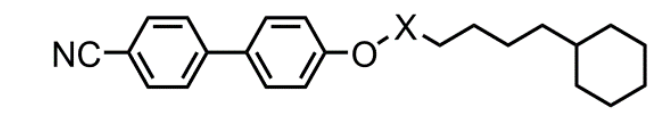

\begin{tabular}{|c|l|ccc|}
\hline & & $\mathbf{M P}$ & $\mathbf{S m A}_{\mathbf{d}}-\mathbf{N}$ & $\mathbf{N}-\mathbf{I s o}$ \\
\hline $\mathbf{9}$ & $\mathbf{T}$ & 97.8 & 82.7 & 85.3 \\
$\left(\mathrm{X}=\mathrm{CH}_{2}\right)$ & $\mathbf{\Delta H}$ & 34.1 & 2.2 & 0.6 \\
\hline $\mathbf{1 1}$ & $\mathbf{T}$ & 85.2 & 71.3 & 75.6 \\
$(\mathrm{X}=\mathrm{C}=\mathrm{O})$ & $\mathbf{\Delta}$ & 34.1 & 0.1 & 0.9 \\
\hline
\end{tabular}

Table 2: $\quad$ Comparison of Transition temperatures $\left(\mathrm{T},{ }^{\circ} \mathrm{C}\right)$ and associated enthalpies $\left(\Delta \mathrm{H}, \mathrm{kJ} \mathrm{mol}^{-1}\right)$ of transition for cyclohexyl- terminated cyanobiphenyls with ether- (5) and ester- (6) linking groups.

The layer spacing of the SmA $A_{d}$ phase of $\mathbf{1 1}$ was measured by SAXS (Figure SI-1)and was found to be temperature independent at $34.3 \AA$, corresponding to a d/I ratio of 1.60 using the molecular length of $21.4 \AA$ (from geometry optimised at the B3LYP/6-31G(d) level). This result, which is the same as for compound $\mathbf{9}$, supports the hypothesis that the enhancements to layer spacing and transition temperatures result from segregation of the bulky end group via reducing the interpenetration of alkyl chains between adjacent smectic layers. Although the end-to-end length (and therefore the aspect ratio) of the antiparallel paired species remains the same with a bulky end group present the effective aspect ratio (i.e. interlayer biphenylbiphenyl distance) is increased due to this reduced interpenetration, leading to higher transition temperatures. Previously we have obtained values of the semi-empirical Kirkwood factor ( $g$, effectively a measure of the degree of pairing in an anisotropic liquid) from measurement of the dielectric anisotropy coupled with calculated dipole moments and polarisabilities. ${ }^{25,31}$ While this information would clearly be desirable for the present materials, the short nematic range of $\mathbf{9}$ and $\mathbf{1 1}$ leads to an unsaturated value of $\Delta \varepsilon$ and therefore of the Kirkwood factor.

We considered that the increase in smectic layer spacing when a bulky group is present could be caused by an increase in the orientational and/or translational order parameters. If we consider the change in layer spacing to be a consequence of size-exclusion effects similar to that observed in the solid state (Figure 3), then we would expect no change in the orientational order parameters. We used the well-known method ${ }^{32-34}$ to determine the orientational order parameters of 9 and $80 C B$ from the WAXS data, and they are presented in Figure 4. The comparison of orientational order parameters in the nematic phase is complicated by the large difference in the temperature range of the nematic phase $\left(\Delta T_{80 \text { с }}>>\Delta T_{9}\right)$, however immediately prior to the SmA-N transition we find values of $\left\langle\mathrm{P}_{2}\right\rangle$ and of $\left\langle\mathrm{P}_{4}\right\rangle$ to be effectively the same for both materials. In the SmA phase we observe that at a given reduced temperature $\left(T_{\text {SmA-N }} / T\right.$ ) both materials have comparable values of $\left\langle\mathrm{P}_{2}\right\rangle$ and $\left\langle\mathrm{P}_{4}\right\rangle$. The presence of a cyclic terminal group does not appear to affect the orientational order of the resulting mesophase, only the degree of positional order via segregation of the bulky cyclic terminal units. This effect 
can be considered as a steric pressure that results from the terminal group at the layer interface, reducing the interpenetration of aliphatic chains in adjacent layers and therefore giving increased layer spacing.

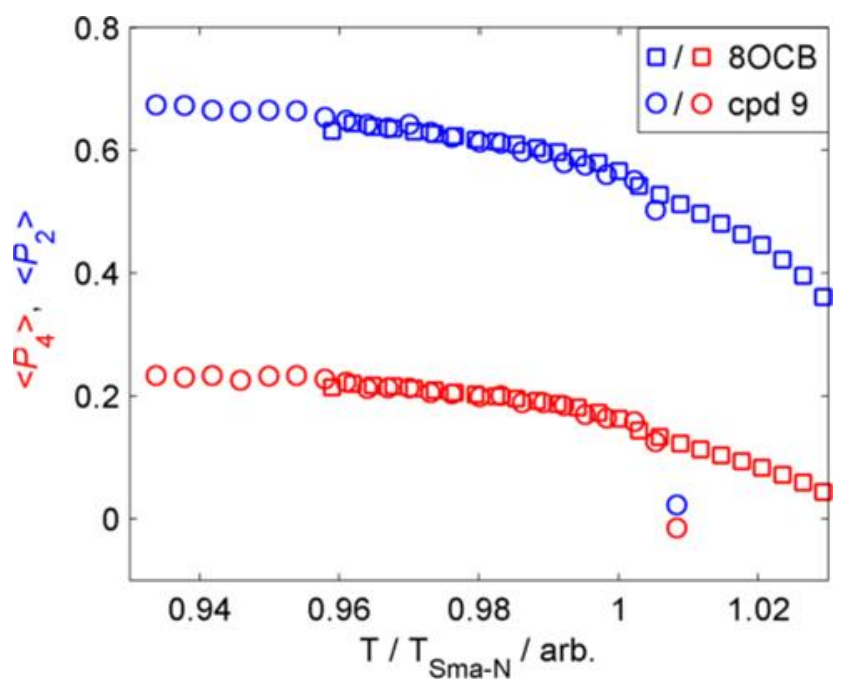

Figure 4: $\quad$ Plot of the first two even $\left\langle\mathrm{P}_{\mathrm{n}}\right\rangle$ order parameters as a function of reduced temperature ( $\left.\mathrm{T} / \mathrm{T}_{\mathrm{SmA}-\mathrm{N}}\right)$ for compound 9 (circles) and 8OCB (squares).

Fully atomistic molecular dynamics simulations were run on 8OCB and 9 to provide a comparison with the experimental data, and using a similar approach to that reported for $110 \mathrm{OB}$ and $t$-Bu-11OCB (11OCB appended with a bulky tertiary butyl end-group). ${ }^{35}$ The simulations were run from isotropic liquid-phase starting geometries of 1440 molecules and at a reduced temperature of $T / T_{\mathrm{c}}=0.934$ for both systems, where $T_{\mathrm{c}}$ is the estimated clearing point of the respective simulated system; the corresponding experimental temperatures are 56.7 and $61.6^{\circ} \mathrm{C}\left(T / T_{\text {Sma-N }}=0.970\right.$ and 0.941$)$ for $80 \mathrm{OB}$ and $\mathbf{9}$, respectively. Details of the methods are given in the SI.

Both simulated systems evolved to form a smectic A phase. The evolution of the orientational order parameters $P_{2}$ and $P_{4}$, obtained using the $\mathrm{N}-\mathrm{O}$ vector as the principal axis, are shown in Figure 5. The evolution of the translational order parameter $\tau$ and associated layer spacing $d$, obtained using the $\mathrm{C}_{4}{ }^{\prime}$ biphenyl carbon atom to define the molecular position, are shown in Figure 6. An analysis of the angle between the director and the layer normal, presented in the SI, confirmed that both simulated systems formed a smectic A phase. The simulated smectic A phase of $80 \mathrm{OCB}$ formed relatively quickly (ca. 60 ns) but was typically not stable (beyond ca. $200 \mathrm{~ns}$ ), whereas that of 9 formed more slowly (ca. $200 \mathrm{~ns}$ ) and was more stable (to at least $1000 \mathrm{~ns}$ ). We attribute the behaviour of 8OCB to the ready formation of diffuse layers in a simulation that lacks long-term stability due to the use of anisotropic pressure coupling, which allows the simulation box aspect ratios to vary and avoids bias from a constrained box shape but which results in an unstable simulation box and phase for this system. By contrast, we attribute the behaviour of $\mathbf{9}$ to the bulky endgroup leading to the slower formation of more ordered layers that give a more stable simulation once formed. 


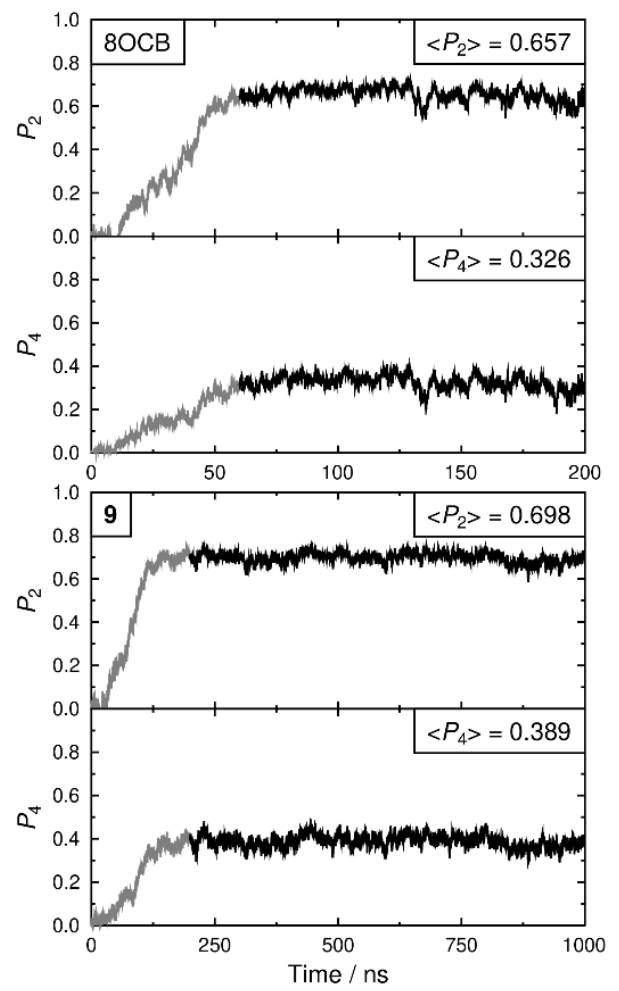

Figure 5 Orientational order parameters, $P_{2}$ and $P_{4}$, from the MD simulations of 8OCB (top) and 9 (bottom) vs. time. The average values given in the insets were determined over the region of each simulation represented by the heavier lines (60-200 ns and 200-1000 ns, respectively). 

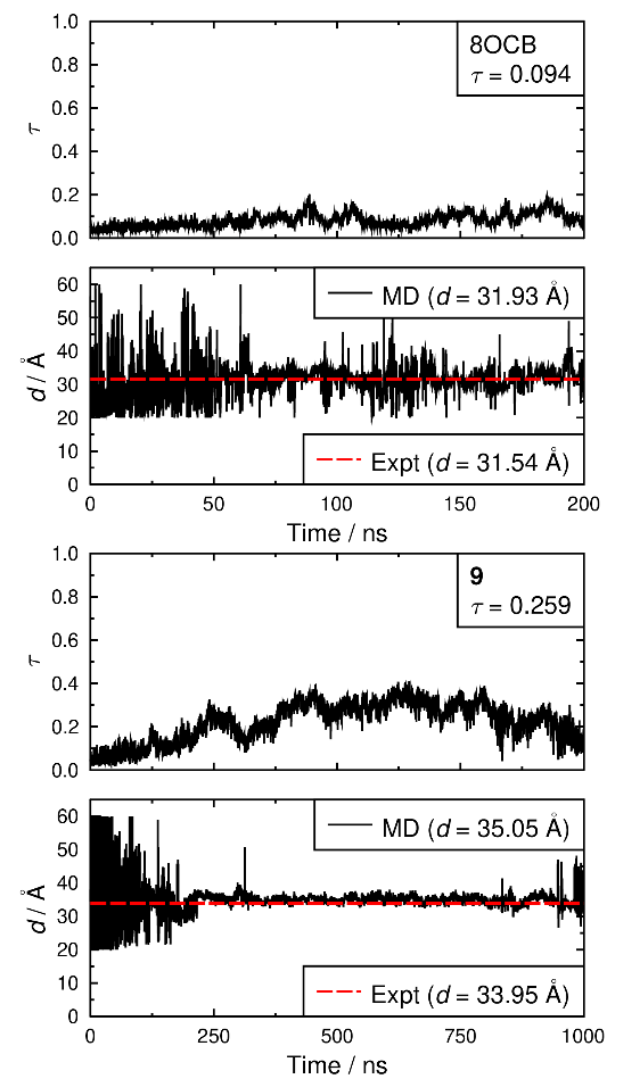

Figure 6: Translational order parameters, $T$, and layer spacings, $d$, from the MD simulations of $80 \mathrm{OB}$ (top) and 9 (bottom). The average MD values given in the insets were determined over times 60-200 ns and 200-1000 ns for 8OCB and 9, respectively, once the phase had formed and was relatively stable. The experimental values of $d$ are given for the closest temperatures at which SAXS data were recorded (56.74 and $61.69^{\circ} \mathrm{C}$, respectively).

In comparison with the respective experimental data at the relevant temperature, these simulated phases give average $P_{2}$ values that are closely similar, average $P_{4}$ values that are slightly higher, and average $d$ values that are closely similar. We do not have experimental data for a comparison with the average $\tau$ values, but together the available comparisons suggest that the simulations may reasonably be used as an aid to interpret the experimental data.

Figure 7 shows snapshots from the simulations of $80 \mathrm{OB}$ and 9 at times when the layers are relatively well-defined, with each molecule represented by a cylinder that corresponds to the $\mathrm{N}-\mathrm{O}$ molecular vector, i.e. the relatively rigid aromatic moiety, used to determine the orientational order parameters. For $80 \mathrm{CB}$, the layers are not very well defined, as indicated also by the relatively low value of $T$, and some of the layers show large ripples. By contrast, the layers of $\mathbf{9}$ are more clearly defined and flatter, with the empty regions between the layers of cylinders in this snapshot containing the cyclohexyl- $\mathrm{C}_{5}$ chains (not shown in this snapshot for clarity). Moreover, an examination of the density of layered atoms along the layer normal vector (comparable to the director) over time showed that the layers of $80 \mathrm{CB}$ often formed for short periods of ca. 10-20 ns before breaking up and then reforming at other locations along the layer normal vector at later times, whereas the layers of $\mathbf{9}$ remained comparatively stable in location once formed. 


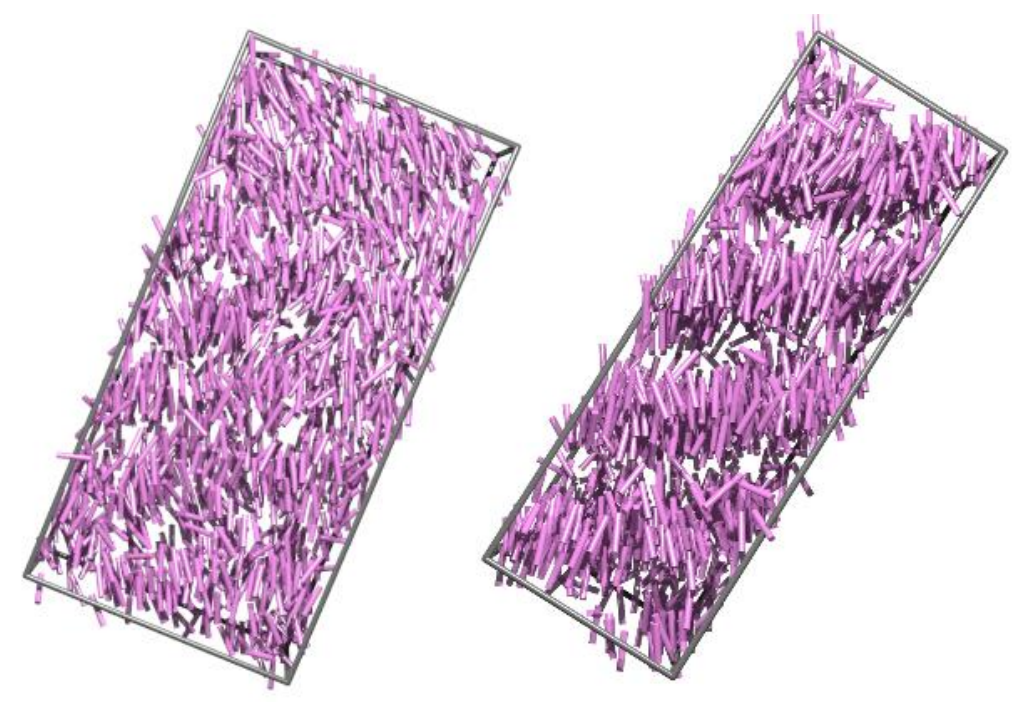

Figure 7: Snapshots of the simulations of $80 C B$ at $75 \mathrm{~ns}$ (left) and 9 at $646 \mathrm{~ns}$ (right), each shown at a time after layer formation has occurred and oriented with the layer normal vector vertical. The purple cylinders representing the molecules are drawn between the nitrogen and oxygen atoms, and the boundaries of the simulation boxes are shown in grey.

The structures of the phases were also assessed using pair-wise correlation functions ${ }^{36}$ of vectors between the $\mathrm{C}_{4}$ and $\mathrm{C}_{4}$ ' biphenyl atoms on all of the molecules, as shown in Figure 8. The radial distribution function $g(r)$ used the centres of the biphenyl vectors, and shows liquid-like distributions with peaks at ca. 5.1 and $9.9 \AA$ for both 8OCB and 9, corresponding to "shells" of surrounding molecules, and tending towards 1 at longer distances indicating long-range disorder; the slightly higher $g(r)$ values for 9 than $80 \mathrm{CB}$ are consistent with a slightly more ordered phase. The first-order orientational correlation functions $G_{1}(r)$ of the biphenyl vectors in $80 \mathrm{OB}$ and 9 both show a negative peak at ca. $3-4 \AA$ corresponding to antiparallel molecular orientations of the biphenyl units being favoured in the first shell, and a weaker positive peak at ca. $7 \AA$ corresponding to parallel molecular orientations being favoured more weakly in the next shell (as illustrated schematically in Figure $2 \mathrm{c}$ and $\mathrm{d}$ ); this observation is consistent with those reported from simulations of other related $\mathrm{nCB}$ and nOCB systems. ${ }^{36,37}$ The second-order orientational correlation function $G_{2}(r)$ used the same biphenyl reference vector, and shows a peak at ca. $5 \AA$ indicating a very high $P_{2}$ orientational order in the first shell that decreases towards values of $\left\langle P_{2}\right\rangle^{2}$ at longer distances, as expected. ${ }^{36}$ Taken together, the distribution functions in Figure 7 show that the ordering behaviour of the biphenyl groups of 8OCB and 9 are similar, which suggests that the differences in smectic layer formation and stability are strongly influenced by the nature of the alkyl chains at the other ends of these molecules. 


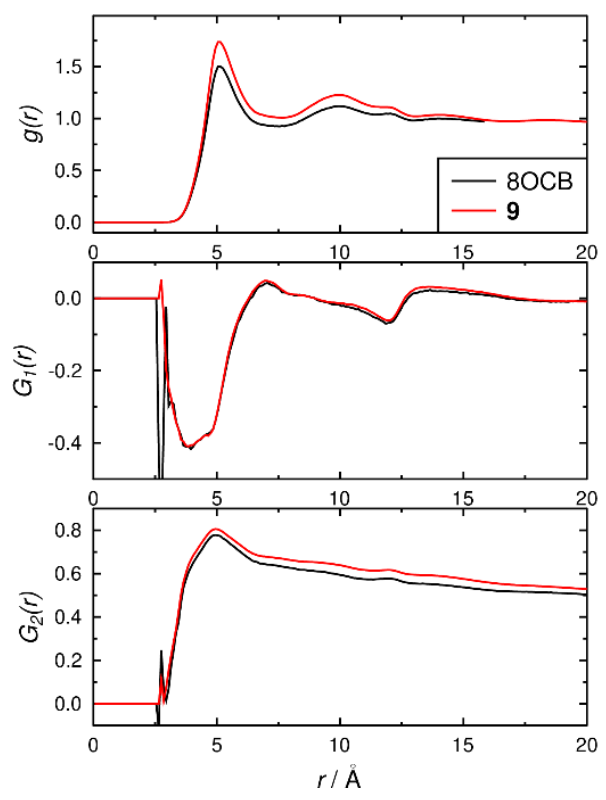

Figure 8: Pair-wise correlation functions determined over the time ranges $60-200$ ns for $80 C B$ and $200-1000$ ns for 9.

The extent of layering and interdigitation of the molecules was assessed using a similar approach to that reported for 110CB and $t$-Bu-11OCB. ${ }^{35}$ Figure 9 shows the relative populations along the layer normal vector, $z$, of a selected head-group atom $\left(\mathrm{C}_{4}{ }^{\prime}\right.$ biphenyl for both $80 \mathrm{CB}$ and 9 , as used to determine $\tau$ values) and a selected tail-group atom (the terminal carbon atom; $\mathrm{C}_{8}$ alkyl for $8 \mathrm{OCB}$, and $\mathrm{C}_{4}$ cyclohexyl for 9 ) during a 50 ns window when the layer positions were relatively stable in each simulation box. All of the relative populations have an approximately sinusoidal form, as shown by the black lines in Figure 9, with the populations of the head-group and tail-group atoms being out of phase, which indicates the presence of distinct aromatic and aliphatic regions along the layer normal. The amplitude of the oscillations is low for $80 \mathrm{CB}$, illustrating the diffuse nature of the layers, and much higher for $\mathbf{9}$, showing the greater degree of nanosegregation between its aromatic and aliphatic moieties.

Figure 9 also shows the relative populations for molecules with the $\mathrm{C}-\mathrm{N}$ vector pointing "up" (red) or "down" (blue) along the z-axis, which corresponds to molecules having their alkyl chains below or above the aromatic moiety, respectively, along this axis (as illustrated schematically in Figure $2 \mathrm{c}$ and d). In Figure 9, the head-group atoms of 8OCB and 9, and the tail-group atoms of $8 \mathrm{OCB}$, show only a small difference in the relative populations of the "up" and "down" molecules along the $z$-axis, which indicates a significant degree of interdigitation of the aromatic head-groups of $8 \mathrm{OCB}$ and $\mathbf{9}$, and of the linear alkyl tail groups of $8 \mathrm{OCB}$. By contrast, the cyclic tail-group atoms of $\mathbf{9}$ show relative populations of "up" and "down" molecules that are distinctly offset along the $z$-axis, with the "up" molecules (cyclohexyl group at the bottom) being higher on the $z$-axis than that of the "down" molecules (cyclohexyl group at the top), which indicates a relatively low degree of interdigitation for the cyclic tail groups of $\mathbf{9}$. 


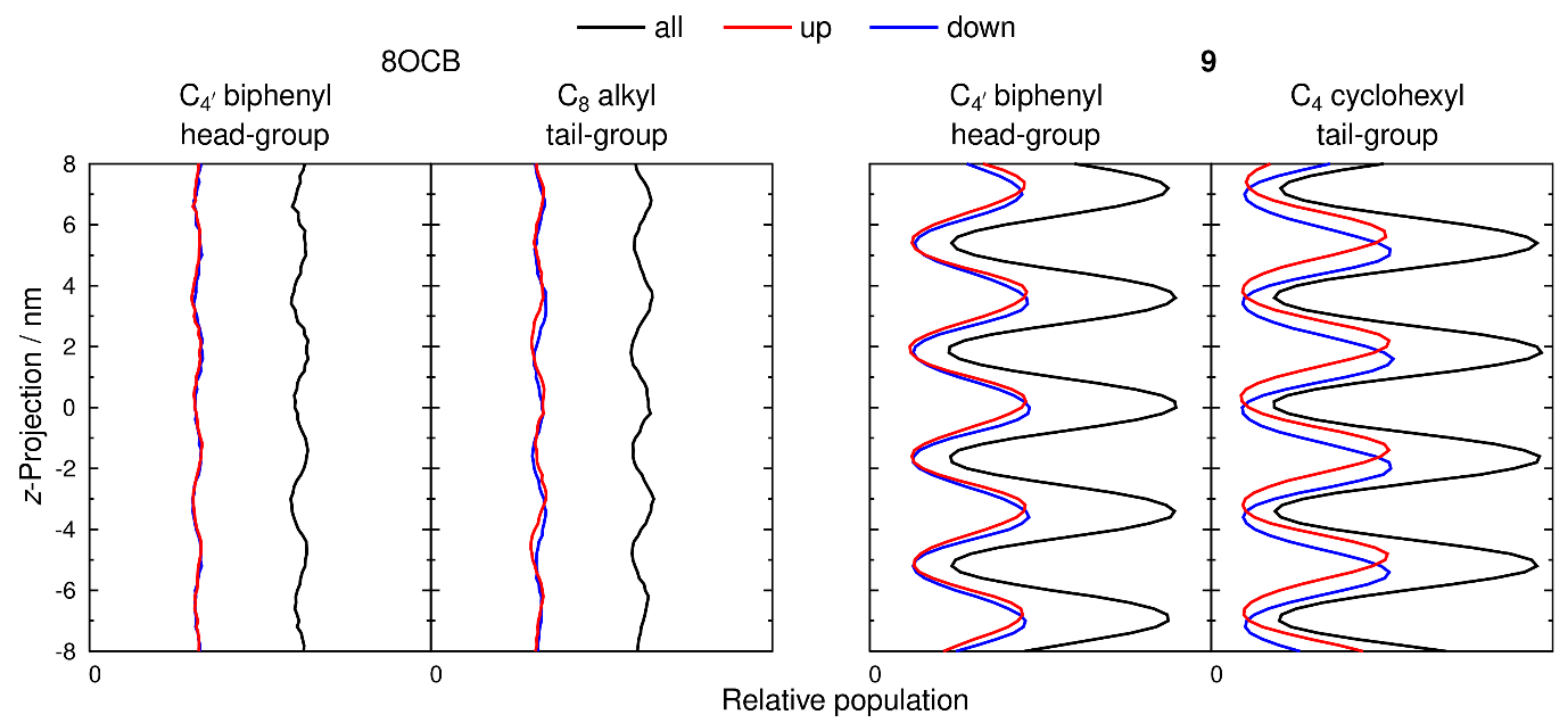

Figure 9: Relative populations along the layer normal, $z$, of head-group and tail-group atoms of $80 \mathrm{CB}$ (left) and 9 (right), calculated over a $50 \mathrm{~ns}$ period of each simulation (100-150 ns and 600-650 ns, respectively) and generated with $0.2 \mathrm{~nm}$ bin-widths. Black lines show the positions for all molecules, whereas red and blue lines represent molecules pointing up and down, respectively. The $z$-projection was defined as zero at the centre of the simulation box and population scales are consistent between plots.

The distributions shown in Figure 9 were used to quantify the extent of interdigitation. ${ }^{35}$ The C4' biphenyl head group atoms of $80 \mathrm{CB}$ and 9 showed $50 \%$ and $53 \%$ interdigitation, respectively, corresponding to approximately half of these head-group atoms being located in the adjacent layer. The C8 alkyl tail group atoms of $80 \mathrm{OB}$ showed $50 \%$ interdigitation, similar to the head groups, whereas the C4 cyclohexyl tail group atoms of $\mathbf{9}$ showed a much lower interdigitation of $39 \%$. Hence, $80 \mathrm{CB}$ shows a similar extent of interdigitation at both ends of the molecule, whereas $\mathbf{9}$ shows much less interdigitation of the bulky cyclohexyl tail group than the biphenyl head group. This behaviour is similar to that reported previously for $110 \mathrm{CB}$ and $t$-Bu-110CB, ${ }^{35}$ where the bulky $t$-Bu tail group displayed less interdigitation than the other terminal groups in either system.

The difference in the extent of interdigitation between 8OCB and 9 suggests that the interlayer boundary at the tail end of these molecules is more clearly defined for 9 than 8OCB. This effect is shown clearly by the snapshots in Figure 10, which show the positions and orientations of the five terminal carbon atoms of the alkyl chain of $80 \mathrm{CB}$ and the equivalent carbon atoms of $\mathbf{9}$. For $8 \mathrm{OCB}$, there is clear interdigitation between the alkyl chains of the molecules pointing up and down, and the associated alkyl layers are diffuse. For $\mathbf{9}$, not only are the alkyl layers more defined, but the inter-layer boundary shows two almost distinct sublayers arising from the separation of cyclohexyl groups in molecules pointing up and down. 


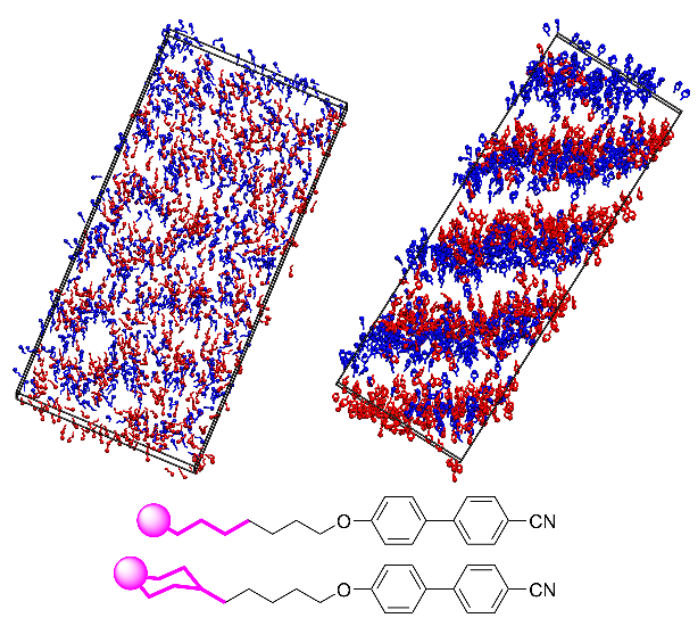

Figure 10: Snapshots of the simulations of $80 C B$ at $75 \mathrm{~ns}$ (left) and 9 at $646 \mathrm{~ns}$ (right) showing the terminal alkyl carbon atoms from $\mathrm{C}_{4}$ onwards, as shown in bold on the structures (bottom); the terminal carbon atoms are represented by spheres to assist orientation. Up and down molecules are coloured red and blue, respectively, and the simulation boxes are oriented with the layer normal vector vertical.

\section{Conclusions}

We have expanded on our previous work using bulky terminal groups to promote the SmA phase in cyanobiphenyl mesogens by using terminal cyclic groups separated from the core using relatively short aliphatic chains. The enhancement to smectic layer spacing observed in cyanobiphenyl materials with bulky terminal groups is a steric effect, and occurs without change in orientational order parameter. Provided a bulky group is present, the layer spacing is $~ 1.6$ times the molecular length regardless of terminal ring size (5), alkyl chain length $(\mathbf{8}, 9$ and $\mathbf{1 0}$ ) and linking group ( 9 and $\mathbf{1 1}$ ). This effect can be exploited to give significant increases to the onset transition temperature of both nematic and smectic mesophases, as demonstrated by comparing compound 9 to its linear analogue. Results from fully atomistic MD simulations support the overall interpretation from experiment that a cyclic end-group on the alkyl chain reduces the interpenetration of molecules between smectic layers in these systems. This phenomenon points to a potentially new method for stabilising both nematic and smectic liquid-crystalline states should the accompanying increase in melting points be countered.

\section{Acknowledgements}

The authors wish to thank the EPSRC for funding through grants EP/M020584/1 and EP/K039660/1. LF acknowledges funding by the Coordenação de Aperfeiçoamento de Pessoal de Nível Superior, Brazil (CAPES), finance code 001. RRP acknowledges funding from the University of York. We thank Dr. Chris Rhodes of the University of York for designing and constructing the LED photoreactor used in the synthesis of compound 2. 


\section{Data Availability}

Raw data pertinent to this work is available on request from the University of York data catalogue (DIO: << add DOI after acceptance >>). Crystal structure data for compounds 1 5 is deposited with the CCDC (deposition numbers 2128187, 2128188, 2128189, 2128190 and 2128191, respectively).

\section{References}

1. T. V. Clapp, W. A. Crossland, A. B. Davey, M. Grasmann, J. P. Hannington, R. K. King, M. Pivnenko, S. Robson, H. Xu, United States Patent no. 8956548, 2015

2. D. J. Gardiner and H. J. Coles, J Phys D Appl Phys, 2006, 39, 4948-4955.

3. J. P. Hannington, T. V. Clapp, F. Nishida, R. K. King, O. Farooq, M. Grasmann, W. A. Crossland, H. J. Coles, A. B. Davey, H. Xu, O. Hadeler, M. Pivnenko, United States Patent No. 8821992, 2014

4. R. J. Mandle, E. J. Davis, J. P. Sarju, N. Stock, M. S. Cooke, S. A. Lobato, S. J. Cowling and J. W. Goodby, J Mater Chem C, 2015, 3, 4333-4344.

5. R. J. Mandle, E. J. Davis, C. C. A. Voll, D. J. Lewis, S. J. Cowling and J. W. Goodby, J Mater Chem C, 2015, 3, 2380-2388.

6. K. M. Mulligan, A. Bogner, Q. X. Song, C. P. J. Schubert, F. Giesselmann and R. P. Lemieux, J Mater Chem C, 2014, 2, 8270-8276.

7. C. P. J. Schubert, A. Bogner, J. H. Porada, K. Ayub, T. Andrea, F. Giesselmann and R. P. Lemieux, J Mater Chem C, 2014, 2, 4581-4589.

8. E. J. Davis, R. J. Mandle, B. K. Russell, P. Y. Foeller, M. S. Cook, S. J. Cowling and J. W. Goodby, Liq Cryst, 2014, 41, 1635-1646.

9. I. Rupar, K. M. Mulligan, J. C. Roberts, D. Nonnenmacher, F. Giesselmann and R. P. Lemieux, J Mater Chem C, 2013, 1, 3729-3735.

10. D. L. Valentine, Nat Rev Microbiol, 2007, 5, 316-323.

11. K. O. Stetter, Philos $T R$ Soc B, 2006, 361, 1837-1842.

12. A. Gliozzi, G. Paoli, M. Derosa and A. Gambacorta, Biochim Biophys Acta, 1983, 735, 234-242.

13. Y. Koga, Archaea, 2012, 789652, DOI:10.1155/2012/789652.

14. J. S. S. Damste, S. Schouten, E. C. Hopmans, A. C. T. van Duin and J. A. J. Geenevasen, J Lipid Res, 2002, 43, 1641-1651.

15. G. Lecollinet, A. Gulik, G. Mackenzie, J. W. Goodby, T. Benvegnu and D. Plusquellec, Chem-Eur J, 2002, 8, 585-593.

16. S. J. Cowling, A. W. Hall and J. W. Goodby, Liq Cryst, 2005, 32, 1483-1498.

17. S. J. Cowling and J. W. Goodby, Chem Commun, 2006, DOI: 10.1039/b610154b, 4107-4109.

18. C. P. Johnston, R. T. Smith, S. Allmendinger and D. W. C. MacMillan, Nature, 2016, 536, 322-325.

19. T. Qin, J. Cornella, C. Li, L. R. Malins, J. T. Edwards, S. Kawamura, B. D. Maxwell, M. D. Eastgate and P. S. Baran, Science, 2016, 352, 801-805.

20. L. J. Perez, W. L. Ng, P. Marano, K. Brook, B. L. Bassler and M. F. Semmelhack, J Med Chem, 2012, 55, 9669-9681.

21. Y. F. Tian, A. B. Ling, R. Fang, R. X. Tan and Z. Q. Liu, Green Chem, 2018, 20, 3432-3435.

22. M. J. Frisch, G. W. Trucks, H. B. Schlegel, G. E. Scuseria, M. A. Robb, J. R. Cheeseman, G. Scalmani, V. Barone, B. Mennucci, G. A. Petersson, H. Nakatsuji, M. Caricato, X. Li, H. P. Hratchian, A. F. Izmaylov, J. Bloino, G. Zheng, J. L.

Sonnenberg, M. Hada, M. Ehara, K. Toyota, R. Fukuda, J. Hasegawa, M. Ishida, T. Nakajima, Y. Honda, O. Kitao, H. Nakai, T. Vreven, J. A. Montgomery Jr., J. E. 
Peralta, F. Ogliaro, M. J. Bearpark, J. Heyd, E. N. Brothers, K. N. Kudin, V. N. Staroverov, R. Kobayashi, J. Normand, K. Raghavachari, A. P. Rendell, J. C. Burant, S. S. lyengar, J. Tomasi, M. Cossi, N. Rega, N. J. Millam, M. Klene, J. E. Knox, J. B. Cross, V. Bakken, C. Adamo, J. Jaramillo, R. Gomperts, R. E. Stratmann, O. Yazyev, A. J. Austin, R. Cammi, C. Pomelli, J. W. Ochterski, R. L. Martin, K. Morokuma, V. G. Zakrzewski, G. A. Voth, P. Salvador, J. J. Dannenberg, S. Dapprich, A. D. Daniels, Ö. Farkas, J. B. Foresman, J. V. Ortiz, J. Cioslowski and D. J. Fox, Gaussian 09 rev E.01, 2009.

23. W. Humphrey, A. Dalke and K. Schulten, J Mol Graph Model, 1996, 14, 33-38.

24. M. Tarini, P. Cignoni and C. Montani, leee T Vis Comput Gr, 2006, 12, 1237-1244.

25. R. J. Mandle, S. J. Cowling, I. Sage, M. E. Colclough and J. W. Goodby, J Phys Chem B, 2015, 119, 3273-3280.

26. A. J. Leadbetter, J. C. Frost, J. P. Gaughan, G. W. Gray and A. Mosley, J. Phys. France, 1979, 40, 375-380.

27. A. LeCalvez, S. Montant, E. Freysz, A. Ducasse, X. W. Zhuang and Y. R. Shen, Chem Phys Lett, 1996, 258, 620-625.

28. S. Maisch, A.-M. Krause, D. Schmidt and M. Lehmann, Liq Cryst, 2017, 45, 136-151

29. J. W. Goodby, R. J. Mandle, E. J. Davis, T. Zhong and S. J. Cowling, Liq Cryst, 2015, 42, 593-622.

30. R. J. Mandle and J. W. Goodby, Reaction Chemistry \& Engineering, 2018, 3, 515519.

31. R. J. Mandle and J. W. Goodby, Liq Cryst, 2017, 44, 656-665.

32. P. Davidson, D. Petermann and A. M. Levelut, J Phys li, 1995, 5, 113-131.

33. M. T. Sims, L. C. Abbott, R. M. Richardson, J. W. Goodby and J. N. Moore, Liq Cryst, 2018, 46, 11-24.

34. D. M. Agra-Kooijman, M. R. Fisch and S. Kumar, Liq Cryst, 2018, 45, 680-686.

35. M. T. Sims, L. C. Abbott, J. W. Goodby and J. N. Moore, Soft Matter, 2019, 15, 77227732.

36. M. F. Palermo, A. Pizzirusso, L. Muccioli and C. Zannoni, 2013, 138, 204901.

37. R. Pecheanu and N. M. Cann, Phys Rev E, 2010, 81, 041704. 


\section{Supplementary Information}

\section{General Methods:}

\subsection{Synthetic Methods}

Unless otherwise noted, chemical reagents were purchased from commercial suppliers and used without further purification. 4,4'-ditertbutyl-2,2'-bipyridyl was purchased from Sigma Aldrich and used as received. $\mathrm{NiCl}_{2}$.glyme was purchased from Strem and used as received. The metallophotoredox catalyst, $\left[\operatorname{Ir}\left\{\mathrm{dF}\left(\mathrm{CF}_{3}\right) \text { ppy }\right\}_{2}(\mathrm{dtbpy})\right] \mathrm{PF}_{6}$, was prepared in two steps from $\mathrm{IrCl}_{3}$ via the method of Lowry et al. ${ }^{1}$ The $\mathrm{sp}^{3}-\mathrm{sp}^{3}$ metallophotoredox coupling reactions ${ }^{2}$ were performed in $25 \mathrm{ml}$ reaction tubes (Sigma Aldrich, part no. Z515981. Irradiation was from two LED emitters (Mouser, part no. LZ1-10UB00-00U8, $405 \mathrm{~nm}$ peak output, $1050 \mathrm{~mW}$ radiant flux) mounted on anodised aluminium heatsinks (Mouser, part no. 984-ATSEU-077B-C6-R0) at opposite sides of the reaction tube at a distance of approximately $1 \mathrm{~cm}$ from the wall of the reaction tube. The LED and reactor assembly was cooled with a fan during operation. Nickel mediated decarboxylative alkyl-alkyl cross couplings of $\mathrm{N}$ - hydroxyphthalamide esters with organozinc reagents were performed via the method of Qin et al. ${ }^{3}$ 4-(Pent-4-eneyloxy)-4'cyanobiphenyl was prepared as reported previously. ${ }^{4}$ 5-Cyclohexylpentan-1-ol was prepared via the method of Perez et al. in $>95 \%$ yield using lithium aluminium hydride in THF. ${ }^{5} 6$ Cyclohexylhexan-1-ol was prepared according to Liu et al. ${ }^{6} \mathrm{THF}$ and dichloromethane were purchased from Fisher Scientific UK and were dried via passage over activated alumina. Diethyl ether was purchased from Fisher Scientific UK and dried over calcium hydride and distilled prior to use.

Reactions were monitored by thin layer chromatography (TLC) with DCM as the eluent. Silica coated aluminium TLC plates used were purchased from Merck (Kieselgel 60 F-254) and visualised using either UV light (254 nm and $365 \mathrm{~nm}$ ), or by oxidation with either iodine or aqueous potassium permanganate solution. Yields refer to chromatographically (HPLC) and spectroscopically $\left({ }^{1} \mathrm{H}\right.$ NMR, ${ }^{13} \mathrm{C}\left\{{ }^{1} \mathrm{H}\right\}$ NMR) homogenous material. 


\subsection{Characterisation Methods}

\subsubsection{Nuclear Magnetic Resonance (NMR)}

NMR spectra were recorded on a JEOL ECS spectrometer operating at $400 \mathrm{MHz}\left({ }^{1} \mathrm{H}\right)$ or 100.5 $\mathrm{MHz}\left({ }^{13} \mathrm{C}\left\{{ }^{1} \mathrm{H}\right\}\right)$ as solutions in $\mathrm{CDCl}_{3}$.

\subsubsection{Mass Spectrometry (MS)}

Mass spectra were recorded on a Bruker compact time of flight mass spectrometer with both ESI and APCI sources, and we extend our gratitude to Mr. Karl Heaton of the University of York for obtaining MS data.

\subsubsection{High Performance Liquid Chromatography (HPLC)}

High-performance liquid chromatography was performed on a Shimadzu Prominence modular HPLC system comprising a LC-20A solvent pump, a DGU-20A $\mathrm{A}_{5}$ degasser, a SIL-20A autosampler, a CBM-20A communication bus, a CTO-20A column oven, and a SPO-20A dual wavelength UV-vis detector operating at wavelengths of 220 and $250 \mathrm{~nm}$. Reverse-phase HPLC was performed using an Alltech bonded silica column with a $5 \mu \mathrm{m}$ pore size, an internal diameter of $4.6 \mathrm{~mm}$ and a length of $250 \mathrm{~mm}$, with neat dichloromethane used as the mobile phase. Chromatograms where only one peak was detected are quoted at $>99.9 \%$ purity.

\subsubsection{Polarised Optical Microscopy (POM)}

Polarised optical microscopy was performed on a Zeiss Axioskop 40Pol microscope using a Mettler FP82HT hotstage controlled by a Mettler FP90 central processor. Photomicrographs were captured via an InfinityX-21 MP digital camera mounted atop the microscope. 


\subsubsection{Differential Scanning Calorimetry (DSC)}

Differential scanning calorimetry was performed on a Mettler DSC822 ${ }^{\mathrm{e}}$ calibrated before use against indium and zinc standards under an atmosphere of dry nitrogen. DSC thermograms were processed in Matlab.

\subsubsection{Small Angle X-ray Scattering (SAXS)}

Small angle X-ray diffraction was performed using a Bruker D8 Discover equipped with a temperature controlled, bored graphite rod furnace, custom built at the University of York. The radiation used was copper Ka $(\lambda=0.154056 \mathrm{~nm})$ from a $1 \mu \mathrm{S}$ microfocus source. Diffraction patterns were recorded on a 2048x2048 pixel Bruker VANTEC 500 area detector set at a distance of $121 \mathrm{~mm}$ from the sample, allowing simultaneous collection of small angle and wide angle scattering data. Samples were filled into $0.9 \mathrm{~mm}$ OD glass capillary tubes and placed into the graphite rod furnace. Alignment of the sample was achieved with a pair of 1T magnets, with the field perpendicular to the incident $X$-ray beam. Diffraction patterns were collected as a function of temperature (controlled to a precision of $+/-0.1^{\circ} \mathrm{C}$ ). Two dimensional diffraction patterns were radially averaged $\left(0.05^{\circ}\right.$ step size) to give one dimensional profiles of scattered intensity as a function of two theta. D-spacings were obtained by fitting the radially averaged data with a Gaussian, Lorentzian or Voigt function, as appropriate.

\subsubsection{Computational Chemistry}

Computational chemistry was performed using Gaussian G09 revision e01 on the York Advanced Research Computing Cluster (YARCC) at various levels of theory as described in the text. ${ }^{7}$ 


\subsection{General Synthetic Protocols}

\subsubsection{General Mitsunobu Procedure:}

An oven dried round bottom flask was charged with 4-hydroxy-4'-cyanobiphenyl (1 eqvl), $\mathrm{PPh}_{3}$ (1.2 eqv) and - if solid - the alcohol (1 eqv). The flask was cooled to $0{ }^{\circ} \mathrm{C}$ with an ice bath under an internal atmosphere of dry nitrogen and the solids dissolved into anhydrous THF (20 $\mathrm{ml}$ ). The reaction solution was cooled to $0{ }^{\circ} \mathrm{C}$ and DIAD (1.2 eqv) and added. The reaction was then monitored by TLC until complete consumption of the phenol and alcohol (typically < $4 \mathrm{~h}$ ). Celite ( $1 \mathrm{~g}$ per mmol of alcohol) was added, the suspension was then stirred for 5 minutes, and the solvent was removed in vacuo. The celite-loaded crude reaction mixture was purified by flash chromatography with a gradient of hexanes/DCM. The chromatographed material was redisolved into $\mathrm{DCM}$ and passed through a $0.2 \mu \mathrm{m}$ syringe filter before removing the solvent in vacuo and recrystallizing from ethanol/THF mixtures.

\subsubsection{General Esterification Procedure:}

The liquid carboxylic acid (1.2 eqv) was added in one portion to a stirred suspension of 4hydroxy-4'-cyanobiphenyl (1 eqv) EDAC (1.5 eqv) DMAP (catalytic) in DCM (5 ml per mmol). The reaction was monitored by the consumption of 4-hydroxy-4'-cyanobiphenyl $\left(\operatorname{Rf}_{\mathrm{DCM}} \sim 0.3\right)$ and the formation of the product $\left(\mathrm{Rf}_{\mathrm{DCM}} \sim 0.65\right)$ as evidenced by TLC. The solvent was removed in vacuo and the crude reaction residue purified by chromatography with a gradient of hexanes/DCM. The chromatographed material was redisolved into DCM and passed through a $0.2 \mu \mathrm{m}$ syringe filter before removing the solvent in vacuo and recrystallizing from ethanol/THF mixtures. 
2. Synthesis of Intermediates

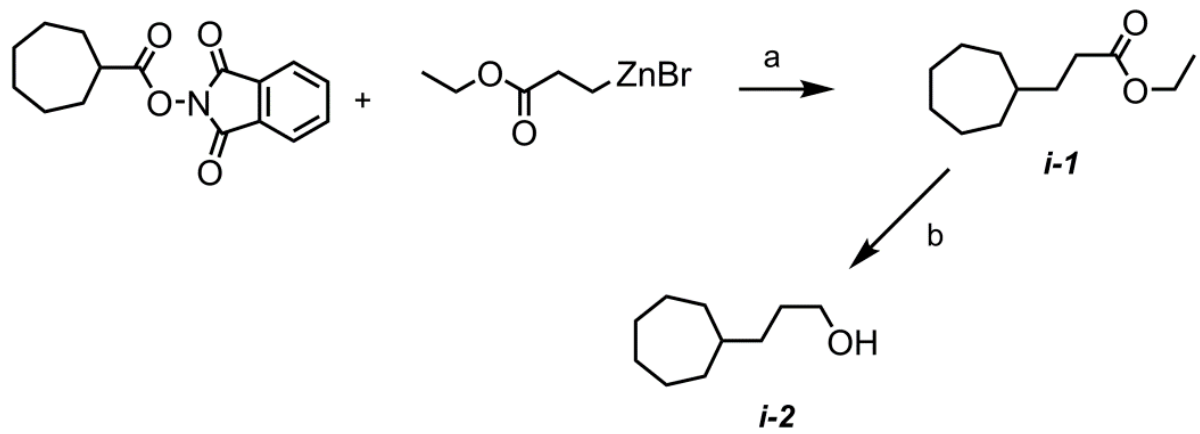

a... $\mathrm{NiCl}_{2 .}$ glyme, dtbbpy, DMF/THF, Ar, $48 \mathrm{~h}$

b... $\mathrm{LiAlH}_{4}$, THF, Ar, $0.5 \mathrm{~h}$

Scheme SI-1 


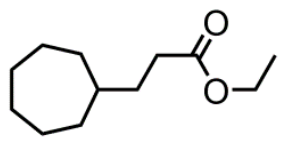

\section{i-1: $\quad$ Ethyl 3-cycloheptylpropanoate}

Nickel chloride ethyleneglycoldimethylether complex ( $\mathrm{NiCl}_{2}$. glyme, $\left.0.1 \mathrm{mmol}, 21.9 \mathrm{mg}\right), 4,4$ 'ditertbutyl-2,2'-bipyridyl (dtbbpy, $53.6 \mathrm{mg}, 0.2 \mathrm{mmol}$ ) and cycloheptyl NHPI-ester ( $1 \mathrm{mmol}, 287$ $\mathrm{mg}$ ) were dissolved into freshly distilled DMF $(6 \mathrm{ml})$ under an atmosphere of dry argon by stirring for 5 minutes, giving a turquoise solution. To this solution was added (3-ethoxy-3oxypropyl)zinc bromide ( $3 \mathrm{mmol}, 0.5 \mathrm{M}$ in THF, $6 \mathrm{ml}$ ) in one portion prompting a colour change to red and then black. The solution was stirred and periodically monitored by TLC (staining with $\mathrm{KMnO}_{4}$ ). The reaction was deemed complete upon complete consumption of the NHPIester $\left(\mathrm{Rf}_{\mathrm{DCM}} \approx 0.5\right)$ and the formation of a new product $\left(\mathrm{Rf}_{\mathrm{DCM}} \approx 0.65\right)$. The solvent was removed in vacuo and the target compound obtained as a colourless oil (with a sweet, fruity aroma) by flash chromatography with pentane/DCM as the eluent.

Spectral data was consistent with literature values. ${ }^{8}$

Yield: $\quad 130 \mathrm{mg}(66 \%)$

$\operatorname{Rf}(\mathrm{DCM}): \quad 0.65$

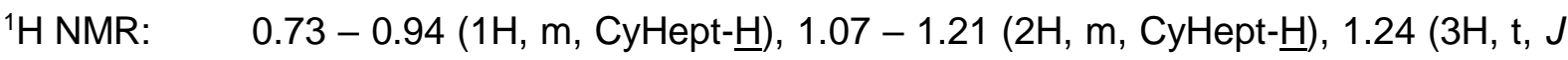
$\left.=7.3 \mathrm{~Hz}, \mathrm{COO}-\mathrm{CH}_{2} \underline{\mathrm{C}}_{3}\right), 1.30-1.77\left(12 \mathrm{H}, \mathrm{m},-\underline{\mathrm{C}}_{2^{-}}+\mathrm{CyHept}-\underline{\mathrm{H}}\right), 2.27(2 \mathrm{H}, \mathrm{t}$, $J=7.3 \mathrm{~Hz}$, CyHept- $\left.\mathrm{CH}_{2} \underline{\mathrm{CH}}_{2}-\mathrm{COO}-\right), 4.10\left(2 \mathrm{H}\right.$, Quartet, $J=7.3 \mathrm{~Hz}, \mathrm{COO}-\underline{\mathrm{C}}_{2}-$ $\left.\mathrm{CH}_{3}\right)$

${ }^{13} \mathrm{C}\left\{{ }^{1} \mathrm{H}\right\}$ NMR: $14.36,26.44,28.60,32.60,33.11,34.31,38.90,60.27,174.31$

MS (ESI): $\quad 199.1696 \quad$ (calcd. for $\mathrm{C}_{12} \mathrm{H}_{23} \mathrm{O}_{2}: \quad$ 199.1693, $\mathrm{M}+\mathrm{H}$ )

221.1519 (calcd. for $\mathrm{C}_{12} \mathrm{H}_{22} \mathrm{NaO}_{2}: \quad 221.1512, \mathrm{M}+\mathrm{Na}$ ) 
<smiles>OCCCC1CCCCCC1</smiles>

i-2: 3-cycloheptylpropan-1-ol

i-1 (100 mg, $0.51 \mathrm{mmol}$ ) was dissolved into anhydrous THF (5 ml) under an atmosphere of dry argon. Solid $\mathrm{LiAlH}_{4}(2 \mathrm{mmol}, 74 \mathrm{mg})$ was added in one portion. The reaction was monitored by TLC; complete consumption of the starting material was noted after 30 minutes. The reaction was quenched with $1 \mathrm{ml}$ of ethyl acetate (minor gas evolution) and the resulting suspension filtered through a pad of silica gel, which was subsequently washed with ethyl acetate $(3 \times 20 \mathrm{ml})$. The combined organics were concentrated in vacuo to afford the title compound as a viscous liquid with a foul odour.

Yield: $\quad 68 \mathrm{mg}(93 \%)$

$\operatorname{Rf}(\mathrm{DCM}): \quad 0.37$

${ }^{1} \mathrm{H}$ NMR: $\quad 1.10-1.30\left(5 \mathrm{H}, \mathrm{m}, \mathrm{CyHept} \underline{\mathrm{H}}+-\mathrm{C}_{2_{2}}\right), 1.33-1.70\left(12 \mathrm{H}, \mathrm{m}, \mathrm{CyHept} \underline{\mathrm{H}}+-\mathrm{C}_{2^{-}}\right.$ ), $3.62\left(2 \mathrm{H}, \mathrm{t}, \mathrm{J}=6.6 \mathrm{~Hz}, \mathrm{CH}_{2}-\mathrm{C}_{2}-\mathrm{OH}\right) \mathrm{OH}$ proton not observed

${ }^{13} \mathrm{C}\left\{{ }^{1} \mathrm{H}\right\}$ NMR: $26.61,28.56,30.83,34.21,39.20,63.58$

MS (ESI): $\quad 157.1527 \quad$ (calcd. for $\mathrm{C}_{10} \mathrm{H}_{20} \mathrm{O}: \quad 157.1587, \mathrm{M}+\mathrm{H}$ ) 


\section{Characterisation of Liquid-Crystalline Chemicals}<smiles>N#Cc1ccc(-c2ccc(OCCCC3CC3)cc2)cc1</smiles>

1: $\quad$ 4'-(3-cyclopropylpropoxy)-[1,1'-biphenyl]-4-carbonitrile

4-(Pent-4-enyloxy)-4'-cyanobiphenyl (506 mg, $2 \mathrm{mmol}$ ) was added to an oven dried flask and dissolved into the minimum quantity of anhydrous diethyl ether $(\sim 10 \mathrm{ml})$ at ambient temperature and under an atmosphere of dry argon. Diethyl zinc $(6 \mathrm{mmol})$ was added in one portion and the solution stirred for 5 minutes. Diiodomethane $(1.6 \mathrm{~g}, 483 \mu \mathrm{l}, 6 \mathrm{mmol})$ was dissolved into anhydrous diethyl ether (total volume $20 \mathrm{ml}$, concentration $\sim 0.3 \mathrm{M}$ ); this solution was then added to the reaction via a syringe pump at a rate of $0.1 \mathrm{ml} \mathrm{min}^{-1}$. The solution became turbid, and was periodically monitored by ${ }^{1} \mathrm{H}$ NMR to determine the ratio of alkene to cyclopropane (the two materials could not be separated by TLC). After $18 \mathrm{~h}$ no alkene was present as judged from ${ }^{1} \mathrm{H}$ NMR and so the reaction was quenched with saturated aqueous ammonium chloride $(5 \mathrm{ml})$. The aqueous layer was subsequently separated and discarded, the organic layer dried over magnesium sulphate and concentrated in vacuo. TLC analysis revealed two major components $\left(\mathrm{Rf}_{\mathrm{DCM}}=0.59\right.$ and $\left.\mathrm{Rf}_{\mathrm{DCM}}=0.05\right)$ with numerous minor components. The crude reaction mixture was separated by flash chromatography with 5:3 hexanes/DCM as the eluent, recrystallization of the chromatographed material from methanol afforded the title compound as a white powder.

Yield: $\quad 290 \mathrm{mg}(54 \%)$

$\operatorname{Rf}(\mathrm{TLC}): \quad 0.59$ (DCM)

${ }^{1} \mathrm{H}$ NMR: $\quad 0.06(2 \mathrm{H}, \mathrm{m}$, CyProp- $\underline{\mathrm{H}}), 0.46(2 \mathrm{H}, \mathrm{m}$, CyProp- $\underline{\mathrm{H}}), 0.67-0.79\left(1 \mathrm{H}, \mathrm{m}, \mathrm{CH}_{2}-\underline{\mathrm{C}} \underline{\mathrm{H}}-\right.$ $\left.\left(\mathrm{CH}_{2}\right)_{2}\right), 1.36$ - $1.42\left(2 \mathrm{H}, \mathrm{m}, \mathrm{ArO}-\left(\mathrm{CH}_{2}\right)_{2}-\mathrm{CH}_{2}-\mathrm{CyProp}\right), 1.87-1.97$ (2H, m, ArO$\left.\mathrm{CH}_{2} \underline{\mathrm{C}}_{2}-\mathrm{CH}_{2}-\mathrm{CyProp}\right), 4.05$ (2H, t, $J=6.4 \mathrm{~Hz}$, ArO- $\left.\underline{\mathrm{H}}_{2}-\mathrm{CH}_{2}\right), 6.99$ (2H, ddd, $J$ $=2.2 \mathrm{~Hz}, J=3.0 \mathrm{~Hz}, J=8.8 \mathrm{~Hz}, \operatorname{Ar} \underline{\mathrm{H}}), 7.52(2 \mathrm{H}, \mathrm{ddd}, J=2.2 \mathrm{~Hz}, J=3.0 \mathrm{~Hz}, J$ $=8.8 \mathrm{~Hz}, \operatorname{Ar} \underline{\mathrm{H}}), 7.64(2 \mathrm{H}, \mathrm{ddd}, J=1.8 \mathrm{~Hz}, J=2.5 \mathrm{~Hz}, J=8.2 \mathrm{~Hz}, \operatorname{Ar} \underline{\mathrm{H}}), 7.70$ $(2 \mathrm{H}, \mathrm{ddd}, J=1.8 \mathrm{~Hz}, J=2.5 \mathrm{~Hz}, J=8.2 \mathrm{~Hz}, \operatorname{Ar} \underline{\mathrm{H}})$

${ }^{13} \mathrm{C}\left\{{ }^{1} \mathrm{H}\right\}$ NMR: $159.92,145.43,132.71,131.38,128.46,127.21,119.28,115.21,110.15$, $67.93,31.14,29.39,10.64,4.62$.

MS (ESI+): $\quad 278.1548$

(calcd. for $\mathrm{C}_{19} \mathrm{H}_{20} \mathrm{NO}: 278.1539, \mathrm{M}+\mathrm{H}$ )

300.1368

(calcd. for $\mathrm{C}_{19} \mathrm{H}_{19} \mathrm{NNaO}: \quad 300.1359, \mathrm{M}+\mathrm{Na}$ )

HPLC: $\quad 99.4 \%$ 
<smiles>N#Cc1ccc(-c2ccc(OCCCC3CCC3)cc2)cc1</smiles>

2: $\quad$ 4'-(3-cyclobutylpropoxy)-[1,1'-biphenyl]-4-carbonitrile

Under a flow of dry nitrogen gas, an oven dried Ace pressure tube equipped with a magnetic stirrer bar and front seal PTFE O-ring was charged with $\operatorname{Ir}\left[\mathrm{dF}\left(\mathrm{CF}_{3}\right) \text { ppy }\right]_{2}(\mathrm{dtbbpy}) \mathrm{PF}_{6}(22.4 \mathrm{mg}$, $0.02 \mathrm{mmol}$ ), $\mathrm{NiCl}_{2}$.glyme (21.9 mg, $0.1 \mathrm{mmol}$ ), 4-4'-ditertbutyl-2,2'-bipyridine (26.8 mg, 0.1 $\mathrm{mmol})$, cyclobutanecarboxylic acid (150 mg, $1.5 \mathrm{mmol})$, caesium carbonate (650 mg, $2 \mathrm{mmol})$, ethyl acetate $(3 \mathrm{ml})$ and acetonitrile $(10 \mathrm{ml})$. The suspension was degassed by agitating in an ultrasonic bath whilst sparging with argon for 30 minutes. Degassed water $(0.4 \mathrm{ml})$ was added, followed by 4-(3-bromopropyloxy)-4'-cyanobiphenyl (316 mg, $1 \mathrm{mmol}$ ). The tube was sealed under a positive pressure of argon, and the reaction mixture was vigorously stirred and irradiated with two LED banks (with peak output at $405 \mathrm{~nm}$ ) for a period of $96 \mathrm{~h}$. The reaction solution was filtered through a pad of celite and concentrated in vacuo to a yellow paste. The crude material was isolated by flash chromatography with 3:2 hexane/DCM as the eluent followed by recrystalisation from methanol, to afford the title compound as a white microcrystalline solid.

Yield: $\quad 122 \mathrm{mg} \mathrm{(42 \% )}$

$\operatorname{Rf}(\mathrm{TLC}): \quad 0.60(\mathrm{DCM})$

${ }^{1} \mathrm{H}$ NMR: $\quad 1.48-1.59\left(2 \mathrm{H}, \mathrm{m},-\mathrm{CH}_{2}-\mathrm{CH}\left(-\mathrm{CH}_{2}-\right)_{2}-\mathrm{CH}_{2}\right), 1.59-1.67\left(2 \mathrm{H}, \mathrm{m},-\mathrm{CH}_{2}-\mathrm{CH}(-\mathrm{C} \underline{\mathrm{H}} \mathrm{H}-\right.$ )$\left._{2}-\mathrm{CH}_{2}\right), 1.67-1.80\left(2 \mathrm{H}, \mathrm{m},-\mathrm{CH}_{2}-\mathrm{CH}(-\mathrm{CH} \underline{\mathrm{H}}-)_{2}-\mathrm{CH}_{2}\right), 1.80-1.94(2 \mathrm{H}, \mathrm{m}, \mathrm{ArO}-$ $\left.\mathrm{CH}_{2}-\mathrm{CH}_{2}-\mathrm{C}_{2}-\mathrm{CyBu}\right), 2.00-2.07\left(2 \mathrm{H}, \mathrm{m}, \mathrm{ArO}-\mathrm{CH}_{2}-\mathrm{CH}_{2}-\mathrm{CH}_{2}-\mathrm{CyBu}\right), 2.32(1 \mathrm{H}$, m, ArO- $\left.\mathrm{CH}_{2}-\mathrm{CH}_{2}-\mathrm{CH}_{2}-\mathrm{CH}-\left(\mathrm{CH}_{2}\right)_{2}-\mathrm{CH}_{2}\right), 6.98(2 \mathrm{H}, \mathrm{d}, J=7.9 \mathrm{~Hz}, \mathrm{Ar} \underline{\mathrm{H}}), 7.53(2 \mathrm{H}$ , d, $J=7.9 \mathrm{~Hz}, \operatorname{Ar} \underline{\mathrm{H}}), 7.64(2 \mathrm{H}, \mathrm{d}, J=8.1 \mathrm{~Hz}, \operatorname{Ar} \underline{\mathrm{H}}), 7.69(2 \mathrm{H}, \mathrm{d}, J=8.1 \mathrm{~Hz}, \operatorname{Ar} \underline{\mathrm{H}})$

${ }^{13} \mathrm{C}\left\{{ }^{1} \mathrm{H}\right\}$ NMR: 18.55, 27.09, 28.46 ,33.35, 35.94, 68.28, 110.16, 115.20, 119.29, 127.22, $128.47,131.39,132.71,145.44,159.92$

MS (ESI+): 292.1694

(calcd. for $\mathrm{C}_{20} \mathrm{H}_{22} \mathrm{NO}: 292.1696, \mathrm{M}+\mathrm{H}$ )

314.1525

(calcd. for $\mathrm{C}_{20} \mathrm{H}_{21} \mathrm{NNaO}: \quad 314.1515, \mathrm{M}+\mathrm{Na}$ )

HPLC: $\quad>99.9 \%$ 


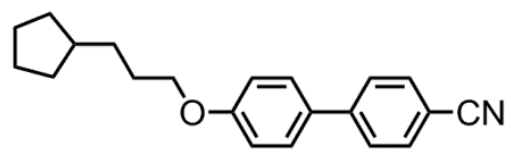

3: $\quad$ 4'-(3-cyclopentylpropoxy)-[1,1'-biphenyl]-4-carbonitrile

Quantities used: 4-hydroxy-4'-cyanobiphenyl (390 mg, 2 mmol), $\mathrm{PPh}_{3}$ (629 mg, $2.4 \mathrm{mmol}$ ), 3cyclopentylpropan-1-ol (256 mg, 2 mmol), DIAD (485 mg, $472 \mu \mathrm{l}, 2.4 \mathrm{mmol})$, THF (20 ml). The general Mitsunobu procedure was followed, affording the title compound as long translucent needles.

Yield: $\quad 520 \mathrm{mg}(75 \%)$

$\operatorname{Rf}(\mathrm{TLC}): \quad 0.54(\mathrm{DCM})$

${ }^{1} \mathrm{H}$ NMR: $\quad 1.04-1.19(2 \mathrm{H}, \mathrm{m}$, CyPent- $\underline{\mathrm{H}}), 1.42-1.69\left(6 \mathrm{H}, \mathrm{m}\right.$, Cypent- $\underline{\mathrm{H}}+\mathrm{ArO}-\mathrm{CH}_{2}-\mathrm{CH}_{2}-$ $\left.\mathrm{C}_{2}\right), 1.72-1.90\left(5 \mathrm{H}, \mathrm{m}, \mathrm{ArO}-\mathrm{CH}_{2}-\mathrm{C}_{2}-\mathrm{CH}_{2}+\right.$ CyPent- $\left.\underline{\mathrm{H}}\right), 4.01(2 \mathrm{H}, \mathrm{t}, J=7.0$ $\left.\mathrm{Hz}, \mathrm{ArO}-\mathrm{CH}_{2}-\mathrm{CH}_{2-}\right), 6.98(2 \mathrm{H}, \mathrm{ddd}, J=2.0 \mathrm{~Hz}, J=2.8 \mathrm{~Hz}, J=8.8 \mathrm{~Hz}, \mathrm{Ar} \underline{\mathrm{H}}$ ), $7.52(2 \mathrm{H}, \mathrm{ddd}, J=2.0 \mathrm{~Hz}, J=2.8 \mathrm{~Hz}, J=8.9 \mathrm{~Hz}, \operatorname{Ar} \underline{\mathrm{H}}), 7.63(2 \mathrm{H}$, ddd, $J=2.0$ $\mathrm{Hz}, J=2.5 \mathrm{~Hz}, J=8.2 \mathrm{~Hz}, \operatorname{Ar} \underline{\mathrm{H}}), 7.68(2 \mathrm{H}, \mathrm{ddd}, J=2.0 \mathrm{~Hz}, J=2.5 \mathrm{~Hz}, J=8.2$ $\mathrm{Hz}, \mathrm{Ar} \underline{\mathrm{H}})$

${ }^{13} \mathrm{C}$ NMR: $\quad 25.30,28.57,32.51,32.80,40.00,68.49,110.09,115.16,119.24,127.15$, $128.41,131.30,132.65,145.37,159.90$,

MS (ESI+): $\quad 306.1866 \quad$ (calcd. for $\mathrm{C}_{21} \mathrm{H}_{24} \mathrm{NO}: 306.1852, \mathrm{M}+\mathrm{H}$ )

328.1683 (calcd. for $\mathrm{C}_{21} \mathrm{H}_{23} \mathrm{NNaO}: \quad 328.1672, \mathrm{M}+\mathrm{Na}$ )

HPLC: $\quad>99.9 \%$ 


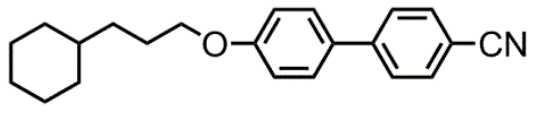

4: $\quad$ 4'-(3-cyclohexylpropoxy)-[1,1'-biphenyl]-4-carbonitrile

Quantities used: 4-hydroxy-4'-cyanobiphenyl (390 mg, 2 mmol), $\mathrm{PPh}_{3}$ (629 mg, $2.4 \mathrm{mmol}$ ), 3cyclohexylpropan-1-ol (284 mg, 2 mmol), DIAD (485 mg, $472 \mu \mathrm{l}, 2.4 \mathrm{mmol}$ ), THF (20 ml). The general Mitsunobu protocol was followed, affording the title compound as a colourless crystalline solid.

Yield: $\quad 590 \mathrm{mg}(92 \%)$

$\operatorname{Rf}(\mathrm{TLC}): \quad 0.54(\mathrm{DCM})$

${ }^{1} \mathrm{H}$ NMR: $\quad 7.69(\mathrm{~d}, \mathrm{~J}=8.2 \mathrm{~Hz}, 2 \mathrm{H}), 7.64(\mathrm{~d}, \mathrm{~J}=8.2 \mathrm{~Hz}, 2 \mathrm{H}), 7.52(\mathrm{~d}, \mathrm{~J}=8.7 \mathrm{~Hz}, 2 \mathrm{H}), 6.99$ $(\mathrm{d}, \mathrm{J}=8.6 \mathrm{~Hz}, 2 \mathrm{H}), 3.99(\mathrm{t}, \mathrm{J}=6.6 \mathrm{~Hz}, 2 \mathrm{H}), 1.91-1.78(\mathrm{~m}, 2 \mathrm{H}), 1.68(\mathrm{~m}, 5 \mathrm{H})$, $1.42-1.31(\mathrm{~m}, 2 \mathrm{H}), 1.31-1.09(\mathrm{~m}, 4 \mathrm{H}), 1.02-0.83(\mathrm{~m}, 2 \mathrm{H})$.

${ }^{13} \mathrm{C}\left\{{ }^{1} \mathrm{H}\right\}$ NMR: $159.94,145.44,132.70,131.37,128.45,127.21,119.28,115.22,110.14$, $68.68,37.59,33.80,33.47,26.79,26.73,26.50$.

MS (ESI+): $\quad 342.1844 \quad$ (calcd for $\mathrm{C}_{22} \mathrm{H}_{25} \mathrm{NNaO}: 342.1828, \mathrm{M}+\mathrm{Na}$ )

HPLC: $\quad>99.9 \%$ 


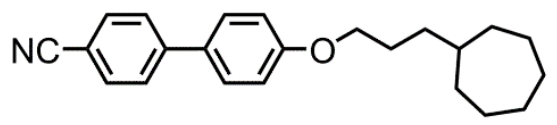

5: $\quad$ 4'-(3-cycloheptylpropoxy)-[1,1'-biphenyl]-4-carbonitrile

Quantities used: 4-hydroxy-4'-cyanobiphenyl (97.5 mg, $0.5 \mathrm{mmol}), \mathrm{PPh}_{3}$ (262 mg, $1 \mathrm{mmol}$ ), 3cyclopentylpropan-1-ol (i-2, $40 \mathrm{mg}, 0.26 \mathrm{mmol}$ ), DIAD (202 mg, $196 \mu \mathrm{l}, 1 \mathrm{mmol})$, THF (2 ml). The general Mitsunobu procedure was followed, affording the title compound as colourless plates following recrystalisation from neat ethanol.

Yield: $\quad 55 \mathrm{mg} \mathrm{(64 \% )}$

$\mathrm{Rf}(\mathrm{TLC}): \quad 0.59(\mathrm{DCM})$

${ }^{1} \mathrm{H}$ NMR: $\quad 1.13-1.27(2 \mathrm{H}, \mathrm{m}, \mathrm{CyHept}-\underline{\mathrm{H}}), 1.33-1.77\left(13 \mathrm{H}, \mathrm{m}, \mathrm{CyHept}-\underline{\mathrm{H}}+-\mathrm{C}_{2_{2}}\right), 1.77-$ $1.87\left(2 \mathrm{H}, \mathrm{m}, \mathrm{CyHept}-\mathrm{CH}_{2}-\mathrm{C}_{2}-\mathrm{CH}_{2} \mathrm{OAr}\right), 3.98\left(2 \mathrm{H}, \mathrm{t}, J=7.0 \mathrm{~Hz}, \mathrm{ArO}-\mathrm{C}_{2}-\mathrm{CH}_{2}-\right.$ $\left.\mathrm{CH}_{2^{-}}\right), 6.99(2 \mathrm{H}, \mathrm{ddd}, J=2.1 \mathrm{~Hz}, J=2.8 \mathrm{~Hz}, J=8.8 \mathrm{~Hz}, \mathrm{Ar} \underline{\mathrm{H}}), 7.53(2 \mathrm{H}$, ddd, $J$ $=2.1 \mathrm{~Hz}, J=2.8 \mathrm{~Hz}, J=8.9 \mathrm{~Hz}, \mathrm{Ar} \underline{\mathrm{H}}), 7.64(2 \mathrm{H}, \mathrm{ddd}, J=2.0 \mathrm{~Hz}, J=2.5 \mathrm{~Hz}, J$ $=8.4 \mathrm{~Hz}, \operatorname{Ar} \underline{\mathrm{H}}), 7.69(2 \mathrm{H}, \mathrm{ddd}, J=2.0 \mathrm{~Hz}, J=2.5 \mathrm{~Hz}, J=8.4 \mathrm{~Hz}, \operatorname{Ar} \underline{\mathrm{H}})$

${ }^{13} \mathrm{C}$ NMR: $\quad 26.61,27.25,28.63,34.45,34.67,39.16,68.66,110.12,115.19,119.27$, $127.19,128.44,131.34,132.69,145.41,159.91$

MS (ESI+): $\quad 334.2175 \quad$ (calcd. for $\mathrm{C}_{23} \mathrm{H}_{28} \mathrm{NO}: 334.2165, \mathrm{M}+\mathrm{H}$ )

356.2001 (calcd. for $\mathrm{C}_{23} \mathrm{H}_{27} \mathrm{NNaO}$ : 356.1985, $\mathrm{M}+\mathrm{Na}$ )

HPLC: $\quad 98.9 \%$ 


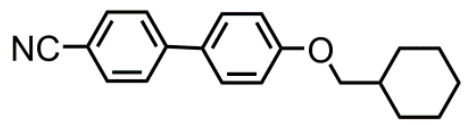

6: $\quad$ 4'-(cyclohexylmethoxy)-[1,1'-biphenyl]-4-carbonitrile

Quantities used: 4-hydroxy-4'-cyanobiphenyl (975 mg, $5 \mathrm{mmol}), \mathrm{PPh}_{3}(1.6 \mathrm{~g}, 6 \mathrm{mmol}$ ), cyclohexylmethanol ( $684 \mathrm{mg}, 6 \mathrm{mmol})$, DIAD (1.2 g, $1.2 \mathrm{ml}, 6 \mathrm{mmol})$, THF (25 ml). The general experimental procedure was followed, affording the title compound as large colourless crystals following recrystalisation from ethanol.

Yield: $\quad 1.3 \mathrm{~g}(89 \%)$

$\operatorname{Rf}(\mathrm{TLC}): \quad 0.51(\mathrm{DCM})$

${ }^{1} \mathrm{H}$ NMR $\quad 1.07(2 \mathrm{H}, \mathrm{qd}, J=3.2 \mathrm{~Hz}, J=12.3 \mathrm{~Hz}, \mathrm{Cy} \underline{\mathrm{H}}), 1.14-1.38(3 \mathrm{H}, \mathrm{m}, \mathrm{Cy} \underline{\mathrm{H}}), 1.65-$ $1.94(6 \mathrm{H}, \mathrm{m}, \mathrm{Cy} \underline{\mathrm{H}}), 3.80\left(2 \mathrm{H}, \mathrm{d}, J=6.4 \mathrm{~Hz}, \mathrm{ArOC}_{2}-\mathrm{Cy}\right), 6.99(2 \mathrm{H}$, ddd, $J=2.2$ $\mathrm{Hz}, J=3.0 \mathrm{~Hz}, J=9.2 \mathrm{~Hz}, \operatorname{Ar} \underline{\mathrm{H}}), 7.52(2 \mathrm{H}, \mathrm{ddd}, J=2.2 \mathrm{~Hz}, J=3.0 \mathrm{~Hz}, J=9.2$ $\mathrm{Hz}, \operatorname{Ar} \underline{\mathrm{H}}), 7.63(2 \mathrm{H}, \mathrm{ddd}, J=1.8 \mathrm{~Hz}, J=2.2 \mathrm{~Hz}, J=8.2 \mathrm{~Hz}, \operatorname{Ar} \underline{\mathrm{H}}), 7.69$ (2H, ddd, $J=1.8 \mathrm{~Hz}, J=2.2 \mathrm{~Hz}, J=8.2 \mathrm{~Hz}, \operatorname{Ar} \underline{\mathrm{H}})$

${ }^{13} \mathrm{C}\left\{{ }^{1} \mathrm{H}\right\}$ NMR: $160.01,145.26,132.55,131.11,128.30,127.03,119.15,115.09,109.96$, 73.62, 37.69, 29.90, 26.53, 25.82.

MS (ESI+): $\quad 292.1707 \quad$ (calcd for $\mathrm{C}_{20} \mathrm{H}_{22} \mathrm{NO}: \quad 292.1696, \mathrm{M}+\mathrm{H}$ )

314.1529 (calcd. for $\mathrm{C}_{20} \mathrm{H}_{21} \mathrm{NNaO}$ : $314.1515, \mathrm{M}+\mathrm{Na}$ )

HPLC: $\quad>99.9 \%$ 


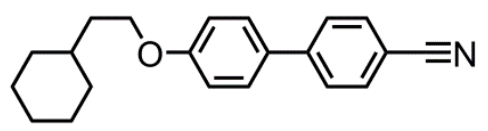

7: $\quad$ 4'-(2-cyclohexylethoxy)-[1,1'-biphenyl]-4-carbonitrile

Quantities used: 4-hydroxy-4'-cyanobiphenyl (975 mg, $5 \mathrm{mmol}$ ), $\mathrm{PPh}_{3}$ (1.6 g, $6 \mathrm{mmol}$ ), 2cyclohexylethanol (768 mg, $6 \mathrm{mmol})$, DIAD (1.2 g, $1.2 \mathrm{ml}, 6 \mathrm{mmol})$, THF (25 ml). The general experimental procedure was followed, affording the title compound as a colourless needles following recrystalisation from ethanol.

Yield: $\quad 1.4 \mathrm{~g} \mathrm{(92 \% )}$

$\operatorname{Rf}(\mathrm{TLC}): \quad 0.48(\mathrm{DCM})$

${ }^{1} \mathrm{H}$ NMR $\quad 0.99(2 \mathrm{H}, \mathrm{qd}, J=2.6 \mathrm{~Hz}, J=12.2 \mathrm{~Hz}, \mathrm{Cy} \underline{\mathrm{H}}), 1.08-1.39(3 \mathrm{H}, \mathrm{m}, \mathrm{Cy} \underline{\mathrm{H}}), 1.53(1 \mathrm{H}$, tquintet, $\left.J=3.4 \mathrm{~Hz}, J=7.0 \mathrm{~Hz}, \mathrm{Cy} \underline{\mathrm{H}}-\mathrm{CH}_{2}\right), 1.62-1.83\left(7 \mathrm{H}, \mathrm{m}, \mathrm{Cy} \underline{\mathrm{H}}+\mathrm{ArO}-\mathrm{CH}_{2}-\right.$ $\left.\mathrm{C}_{2}-\mathrm{Cy}\right), 4.04\left(2 \mathrm{H}, \mathrm{d}, J=7.0 \mathrm{~Hz}, \mathrm{ArOC}_{2}-\mathrm{CH}_{2}-\mathrm{Cy}\right), 7.00(2 \mathrm{H}$, ddd, $J=2.1 \mathrm{~Hz}$, $J=3.0 \mathrm{~Hz}, J=9.2 \mathrm{~Hz}, \operatorname{Ar} \underline{\mathrm{H}}), 7.52(2 \mathrm{H}, \mathrm{ddd}, J=2.1 \mathrm{~Hz}, J=3.0 \mathrm{~Hz}, J=9.2 \mathrm{~Hz}$, Ar프), $7.62(2 \mathrm{H}$, ddd $, J=1.8 \mathrm{~Hz}, J=2.5 \mathrm{~Hz}, J=8.4 \mathrm{~Hz}, \operatorname{Ar} \underline{\mathrm{H}}), 7.67$ (2H, ddd, $J$ $=1.8 \mathrm{~Hz}, J=2.5 \mathrm{~Hz}, J=8.4 \mathrm{~Hz}, \operatorname{Ar} \underline{\mathrm{H}})$

${ }^{13} \mathrm{C}\left\{{ }^{1} \mathrm{H}\right\}$ NMR: $159.81,145.23,132.54,131.15,128.30,127.03,119.13,115.08,109.97$, 66.12, 36.59, 34.54, 33.31, 26.54, 26.26.

MS (ESI+): $\quad 328.1685 \quad$ (calcd for $\mathrm{C}_{21} \mathrm{H}_{23} \mathrm{NNaO}: 328.1672, \mathrm{M}+\mathrm{Na}$ )

HPLC: $\quad 99.7 \%$ 


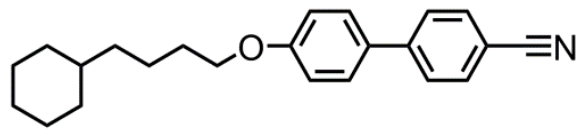

8: $\quad$ 4'-((4-cyclohexylbutyl)oxy)-[1,1'-biphenyl]-4-carbonitrile

Quantities used: 4-hydroxy-4'-cyanobiphenyl (390 mg, 2 mmol), $\mathrm{PPh}_{3}$ (629 mg, $2.4 \mathrm{mmol}$ ), 4cyclohexylbutan-1-ol (312 mg, $2 \mathrm{mmol})$, DIAD (485 mg, $472 \mu \mathrm{l}, 2.4 \mathrm{mmol})$, THF (20 ml). The general Mitsunobu protocol was followed, affording the title compound as a colourless crystalline solid.

Yield: $\quad 510 \mathrm{mg}(77 \%)$

$\operatorname{Rf}(\mathrm{TLC}): \quad 0.51(\mathrm{DCM})$

${ }^{1} \mathrm{H}$ NMR: $\quad 0.80-0.96(2 \mathrm{H}, \mathrm{m}, \mathrm{Cy} \underline{\mathrm{H}}), 1.11-1.30$ (6H, m, Cyㅡㄹ), $1.42-1.54(2 \mathrm{H}, \mathrm{m}, \mathrm{Cy} \underline{\mathrm{H}})$, $1.60-1.86\left(7 \mathrm{H}, \mathrm{m}, \mathrm{Cy} \underline{\mathrm{H}}+\mathrm{ArO}-\mathrm{CH}_{2}-\mathrm{C}_{2}\right), 4.00\left(2 \mathrm{H}, \mathrm{d}, J=6.6 \mathrm{~Hz}, \mathrm{ArOC}_{\mathrm{H}_{2}}-\right.$ $\left.\mathrm{CH}_{2}\right), 6.99(2 \mathrm{H}$, ddd, $J=1.8 \mathrm{~Hz}, J=2.5 \mathrm{~Hz}, J=8.8 \mathrm{~Hz}, \mathrm{Ar} \underline{\mathrm{H}}), 7.52(2 \mathrm{H}$, ddd, $J$ $=1.8 \mathrm{~Hz}, J=2.5 \mathrm{~Hz}, J=8.8 \mathrm{~Hz}, \operatorname{Ar} \underline{\mathrm{H}}), 7.62(2 \mathrm{H}, \mathrm{ddd}, J=2.1 \mathrm{~Hz}, J=2.5 \mathrm{~Hz}, J$ $=8.8 \mathrm{~Hz}, \operatorname{Ar} \underline{\mathrm{H}}), 7.67(2 \mathrm{H}, \mathrm{ddd}, J=2.1 \mathrm{~Hz}, J=2.5 \mathrm{~Hz}, J=8.8 \mathrm{~Hz}, \operatorname{Ar} \underline{\mathrm{H}})$

${ }^{13} \mathrm{C}\left\{{ }^{1} \mathrm{H}\right\}$ NMR: $159.90,145.35,132.63,131.27,128.39,127.13,119.22,115.16,110.07$, $68.26,37.69,37.29,33.47,29.60,26.80,26.51,23.40$.

MS (ESI+): $\quad 334.2176 \quad$ (calcd. for $\mathrm{C}_{23} \mathrm{H}_{28} \mathrm{NO}: 334.2165, \mathrm{M}+\mathrm{H}$ )

356.1999 (calcd. for $\mathrm{C}_{23} \mathrm{H}_{27} \mathrm{NNaO}: \quad 356.1985, \mathrm{M}+\mathrm{Na}$ )

HPLC: $\quad 99.6 \%$ 


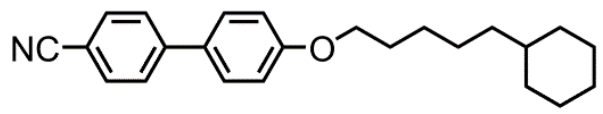

9: $\quad$ 4'-((5-cyclohexylpentyl)oxy)-[1,1'-biphenyl]-4-carbonitrile

Quantities used: 4-hydroxy-4'-cyanobiphenyl (390 mg, 2 mmol), $\mathrm{PPh}_{3}$ (629 mg, $2.4 \mathrm{mmol}$ ), 5cyclohexylpentan-1-ol (340 mg, 2 mmol), DIAD (485 mg, $472 \mu \mathrm{l}, 2.4 \mathrm{mmol}$ ), THF (20 ml). The general Mitsunobu protocol was followed, affording the title compound as a colourless crystalline solid.

Yield: $\quad 570 \mathrm{mg}(82 \%)$

Rf (TLC): $\quad 0.52$ (DCM)

${ }^{1} \mathrm{H}$ NMR: $\quad 0.75-0.97(2 \mathrm{H}, \mathrm{m}, \mathrm{Cy} \underline{\mathrm{H}}), 1.05-1.30\left(6 \mathrm{H}, \mathrm{m}, \mathrm{Cy} \underline{\mathrm{H}}+-\mathrm{CH}_{2}-\mathrm{C}_{3}\right), 1.30-1.53$ $\left(4 \mathrm{H}, \mathrm{m}, \mathrm{Cy} \underline{\mathrm{H}}+-\mathrm{CH}_{2}-\mathrm{C}_{2}-\mathrm{CH}_{3}\right), 1.59-1.74\left(5 \mathrm{H}, \mathrm{m}, \mathrm{Cy} \underline{\mathrm{H}}+\mathrm{ArO}-\mathrm{CH}_{2}-\mathrm{CH}_{2}-\mathrm{C}_{2}-\right.$ $\left.\mathrm{CH}_{2-}\right), 1.76-1.91\left(2 \mathrm{H}, \mathrm{m}, \mathrm{ArO}-\mathrm{CH}_{2}-\mathrm{C}_{2}-\mathrm{CH}_{2}\right), 4.00(2 \mathrm{H}, \mathrm{d}, J=6.6 \mathrm{~Hz}, \mathrm{ArO}-$ $\left.\mathrm{C}_{\underline{H_{2}}}-\mathrm{CH}_{2}\right), 6.99(2 \mathrm{H}$, ddd, $J=2.1 \mathrm{~Hz}, J=2.5 \mathrm{~Hz}, J=8.8 \mathrm{~Hz}, \operatorname{Ar} \underline{\mathrm{H}}), 7.52(2 \mathrm{H}$, ddd, $J=2.1 \mathrm{~Hz}, J=2.5 \mathrm{~Hz}, J=8.8 \mathrm{~Hz}, \operatorname{Ar} \underline{\mathrm{H}}), 7.62(2 \mathrm{H}, \mathrm{ddd}, J=2.1 \mathrm{~Hz}, J=2.5$ $\mathrm{Hz}, J=9.1 \mathrm{~Hz}, \operatorname{Ar} \underline{\mathrm{H}}), 7.67$ (2H, ddd, $J=2.1 \mathrm{~Hz}, J=2.5 \mathrm{~Hz}, J=9.2 \mathrm{~Hz}, \operatorname{Ar} \underline{\mathrm{H}}$ )

${ }^{13} \mathrm{C}\left\{{ }^{1} \mathrm{H}\right\}$ NMR: $159.88,145.32,132.61,131.24,128.37,127.10,119.19,115.14,110.05$, $68.23,37.68,37.50,33.51,29.32,26.81,26.70,26.51,26.42$.

MS (ESI+): $\quad 348.2326 \quad$ (calcd. for $\mathrm{C}_{24} \mathrm{H}_{30} \mathrm{NO}: 348.2322, \mathrm{M}+\mathrm{H}$ ) $370.2156 \quad$ (calcd. for $\mathrm{C}_{24} \mathrm{H}_{29} \mathrm{NNaO}: \quad 370.2141, \mathrm{M}+\mathrm{Na}$ )

HPLC: $\quad 99.3 \%$ 


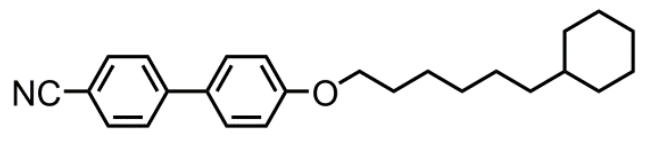

10: $\quad 4$ '-((6-cyclohexylhexyl)oxy)-[1,1'-biphenyl]-4-carbonitrile

Quantities used: 4-hydroxy-4'-cyanobiphenyl (195 mg, $1 \mathrm{mmol}$ ), $\mathrm{PPh}_{3}$ (524 mg, $2 \mathrm{mmol}$ ), 6cyclohexylhexan-1-ol (368 mg, $2 \mathrm{mmol}$ ), DIAD (404 mg, $393 \mu \mathrm{l}, 2.4 \mathrm{mmol})$, THF (4 ml). The general Mitsunobu protocol was followed, affording the title compound as a colourless crystalline solid following recrystalisation from nitromethane.

Yield: $\quad 281 \mathrm{mg}(75 \%)$

$\operatorname{Rf}(\mathrm{TLC}): \quad 0.61$ (DCM)

${ }^{1} \mathrm{H}$ NMR: $\quad 0.75-0.93(2 \mathrm{H}, \mathrm{m}, \mathrm{Cy} \underline{\mathrm{H}}), 1.05-1.26\left(6 \mathrm{H}, \mathrm{m}, \mathrm{C} \underline{\underline{H}}+-\mathrm{CH}_{2}-\underline{\mathrm{C}}_{2}\right), 1.27-1.38$ $\left(4 \mathrm{H}, \mathrm{m}, \mathrm{Cy} \underline{\mathrm{H}}+-\mathrm{CH}_{2}-\mathrm{CH}_{2}-\mathrm{CH}_{2}\right), 1.39-1.50\left(2 \mathrm{H}, \mathrm{m},-\mathrm{CH}_{2}-\mathrm{CH}_{2}-\mathrm{CH}_{2}\right), 1.60-1.72$ $\left(5 \mathrm{H}, \mathrm{m}, \mathrm{Cy} \underline{\mathrm{H}}+\mathrm{ArO}-\mathrm{CH}_{2}-\mathrm{CH}_{2}-\mathrm{CH}_{2}-\mathrm{CH}_{2}\right), 1.75-1.88\left(2 \mathrm{H}, \mathrm{m}, \mathrm{ArO}-\mathrm{CH}_{2}-\mathrm{C}_{2}{ }^{-}\right.$ $\left.\mathrm{CH}_{2}\right), 3.99\left(2 \mathrm{H}, \mathrm{d}, J=6.6 \mathrm{~Hz}, \mathrm{ArO}-\mathrm{CH}_{2}-\mathrm{CH}_{2}\right), 6.98(2 \mathrm{H}, \mathrm{ddd}, J=1.8 \mathrm{~Hz}, J=2.4$ $\mathrm{Hz}, J=8.8 \mathrm{~Hz}, \operatorname{Ar} \underline{\mathrm{H}}), 7.52(2 \mathrm{H}, \mathrm{ddd}, J=1.8 \mathrm{~Hz}, J=2.4 \mathrm{~Hz}, J=8.8 \mathrm{~Hz}, \operatorname{Ar} \underline{\mathrm{H}})$, $7.63(2 \mathrm{H}$, ddd, $J=2.1 \mathrm{~Hz}, J=2.4 \mathrm{~Hz}, J=9.1 \mathrm{~Hz}, \mathrm{Ar} \underline{\mathrm{H}}), 7.68(2 \mathrm{H}, \mathrm{ddd}, J=2.1$ $\mathrm{Hz}, J=2.4 \mathrm{~Hz}, J=9.2 \mathrm{~Hz}, \operatorname{Ar} \underline{\mathrm{H}})$

${ }^{13} \mathrm{C}\left\{{ }^{1} \mathrm{H}\right\}$ NMR: $26.19,26.59,26.89,26.91,29.35,29.84,33.59,37.60,37.79,68.33,110.15$, $115.22,119.27,127.21,128.45,131.37,132.70,145.44,159.94$

MS (APCl+): 362.248399 (calcd. for $\mathrm{C}_{25} \mathrm{H}_{32} \mathrm{NO}: 362.247841, \mathrm{M}+\mathrm{H}$ ) 
<smiles>N#Cc1ccc(-c2ccc(OC(=O)CCCCC3CCCCC3)cc2)cc1</smiles>

11: $\quad 4$ '-cyano-[1,1'-biphenyl]-4-yl 5-cyclohexylpentanoate

5-Cyclohexylpentanoic acid $(1 \mathrm{~g}, 5.4 \mathrm{mmol}$ ) was added dropwise to a suspension of 4hydroxy-4'-cyanobiphenyl (970 mg, $5 \mathrm{mmol})$, EDAC.HCl (1.1 g, $6 \mathrm{mmol}$ ) and DMAP (50 mg) in dichloromethane. The suspension was vigorously stirred and became a homogenous solution within a few minutes. Stirring was continued for $1 \mathrm{~h}$, the solvent was removed in vacuo and the crude residue was purified by flash chromatography with a gradient of hexanes/DCM. The chromatographed material was redisolved into DCM and passed through a $0.2 \mu \mathrm{m}$ syringe filter before removing the solvent in vacuo and recrystallizing from ethanol/THF mixtures.

Yield: $\quad 1.7 \mathrm{~g}(94 \%)$

Rf (TLC): $\quad 0.46(\mathrm{DCM})$

${ }^{1} \mathrm{H}$ NMR: $\quad 0.78-0.97(2 \mathrm{H}, \mathrm{m}, \mathrm{Cy} \underline{\mathrm{H}}), 1.07-1.37\left(6 \mathrm{H}, \mathrm{m},-\mathrm{CH}_{2}-\underline{\mathrm{C}}_{3}+\mathrm{Cy} \underline{\mathrm{H}}\right), 1.38-1.50$ $\left(2 \mathrm{H}, \mathrm{m},-\mathrm{CH}_{2}-\mathrm{C}_{2}-\mathrm{CH}_{2}-\mathrm{CH}_{3}\right), 1.59-1.83\left(7 \mathrm{H}, \mathrm{m}, \mathrm{ArCOO}-\mathrm{CH}_{2} \mathrm{C}_{2}-\mathrm{CH}_{2}+\mathrm{Cy} \underline{\mathrm{H}}\right)$, $2.59\left(2 \mathrm{H}, \mathrm{t}, J=7.5 \mathrm{~Hz}, \operatorname{ArCOO}-\mathrm{C}_{2}-\mathrm{CH}_{2}-\right), 7.20(2 \mathrm{H}, \mathrm{d}, J=8.6 \mathrm{~Hz}, \mathrm{Ar} \underline{\mathrm{H}}), 7.59$ $(2 \mathrm{H}, \mathrm{d}, J=8.6 \mathrm{~Hz}, \operatorname{Ar} \underline{\mathrm{H}}, 7.65(2 \mathrm{H}, \mathrm{d}, J=8.4 \mathrm{~Hz}, \operatorname{Ar} \underline{\mathrm{H}}), 7.71(2 \mathrm{H}, \mathrm{d}, J=8.4 \mathrm{~Hz}$, Ar $\underline{H})$

${ }^{13} \mathrm{C}\left\{{ }^{1} \mathrm{H}\right\}$ NMR: $172.33,151.30,144.85,136.79,132.72,128.39,127.74,122.43,118.95$, $111.06,37.54,37.15,34.51,33.46,26.78,26.48,26.44,25.29$.

MS (ESI+): $\quad 384.1948 \quad$ (calcd. for $\mathrm{C}_{25} \mathrm{H}_{31} \mathrm{NNaO}: \quad 384.1934, \mathrm{M}+\mathrm{Na}$ )

HPLC: $\quad 99.8 \%$ 


\section{Supplemental Data}

\subsection{Supplemental SAXS data}

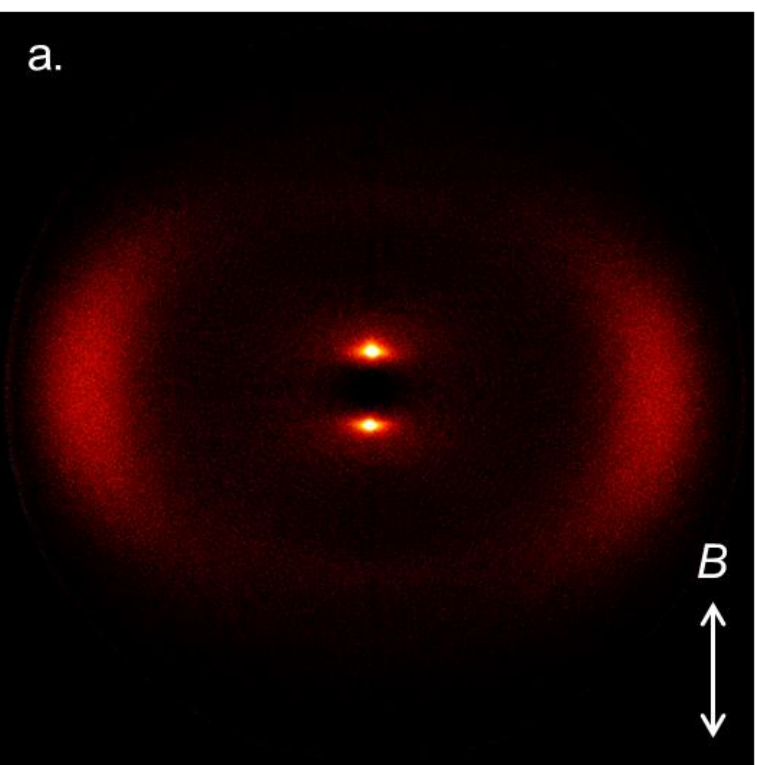

b.

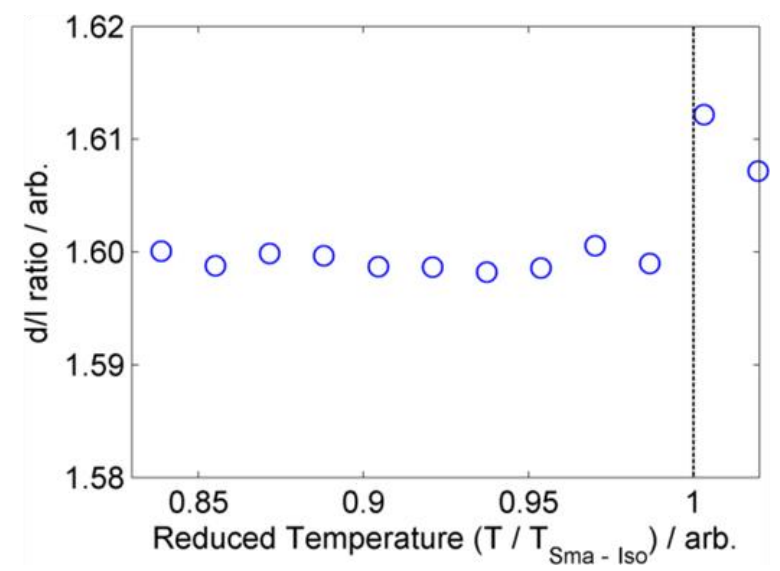

Figure SI-1: (a) two dimensional SAXS pattern obtained for a magnetically aligned sample of compound 11 at a temperature of $65^{\circ} \mathrm{C}$, (b) plot of the $\mathrm{d} / \mathrm{l}$ ratio of compound 11 as a function of reduced temperature ( $T / T_{\text {SmA-N }}$ ) using the molecular length of $21.4 \AA$ Abtained from the B3LYP/6-31G(d) minimised geometry of 11 . 


\subsection{Supplemental Microscopy Data}
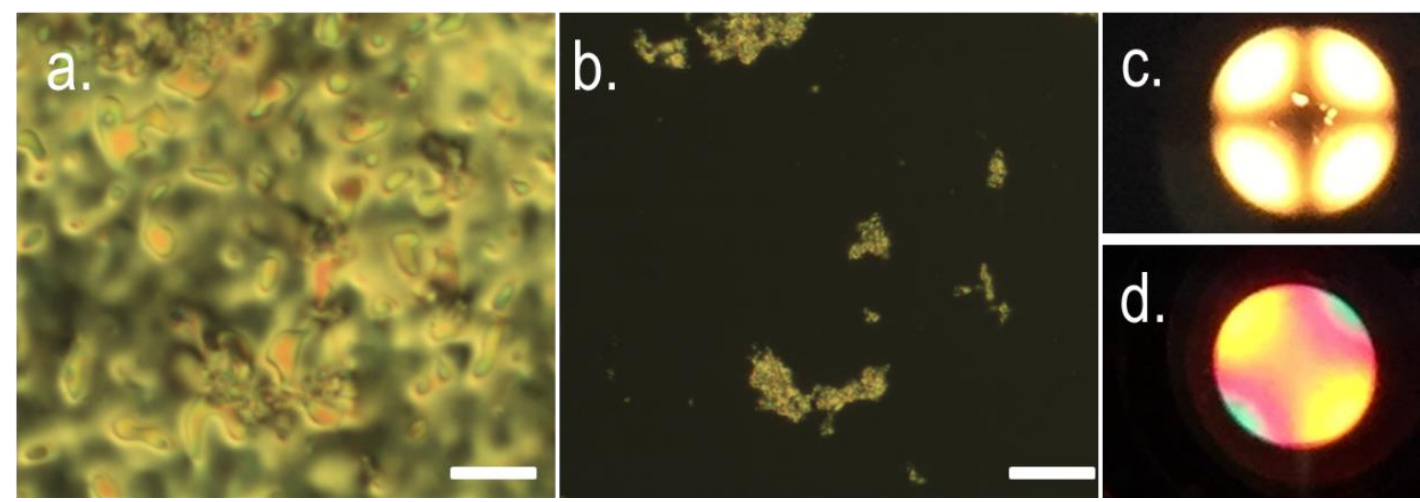

Figure SI-2: $\quad$ Photomicrographs $(x 100$, scale bar $100 \mu \mathrm{m})$ of the nematic phase $\left(\mathrm{a}, 53{ }^{\circ} \mathrm{C}\right)$ and the smectic A phase $\left(47^{\circ} \mathrm{C}\right)$ of compound 8. (c) Conoscopic figure obtained for the smectic A phase demonstrating the phase to be uniaxial, insertion of $a^{1 / 4}$ wave plate (d) demonstrates the phase to be optically positive.
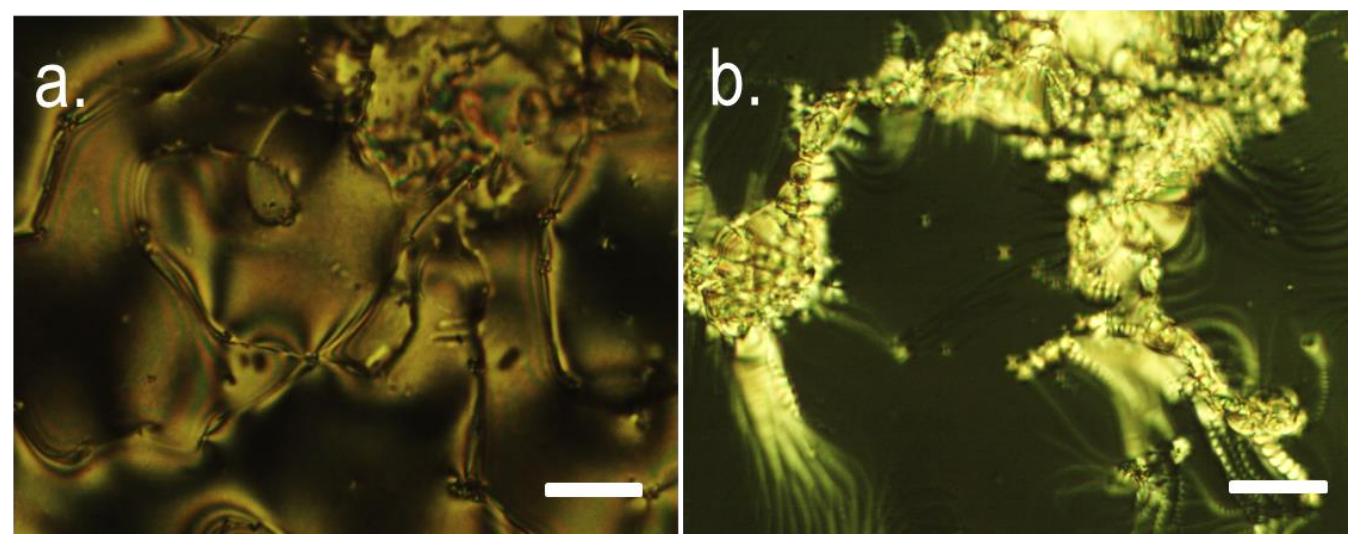

Figure SI-3: $\quad$ Photomicrographs $(x 100$, scale bar $100 \mu \mathrm{m})$ of the nematic phase $\left(\mathrm{a}, 84.3^{\circ} \mathrm{C}\right)$ and the smectic A phase $\left(79.5^{\circ} \mathrm{C}\right)$ of compound 9 . 


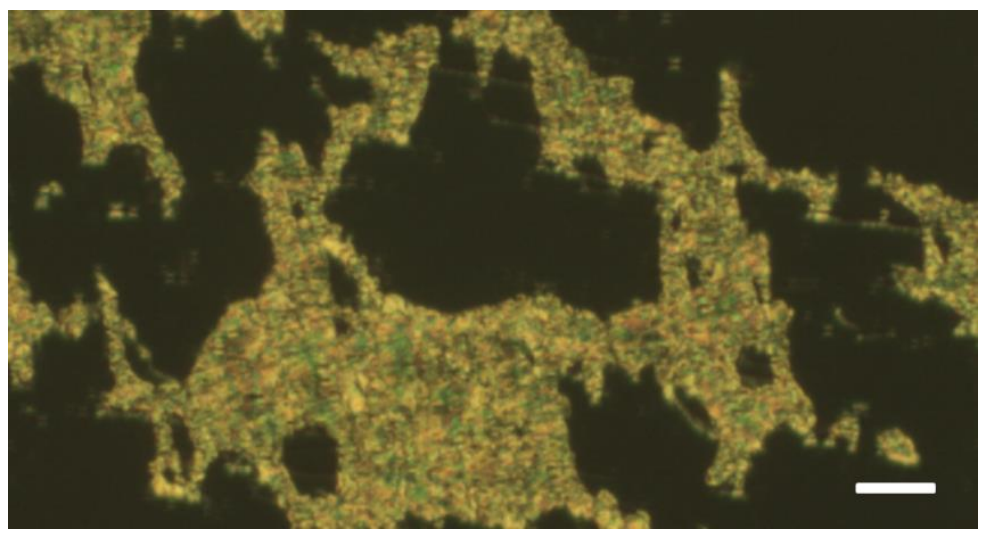

Figure SI-4: Photomicrograph $(\times 100$, scale bar $100 \mu \mathrm{m})$ of the smectic A phase of 10 at 66 ${ }^{\circ} \mathrm{C}$
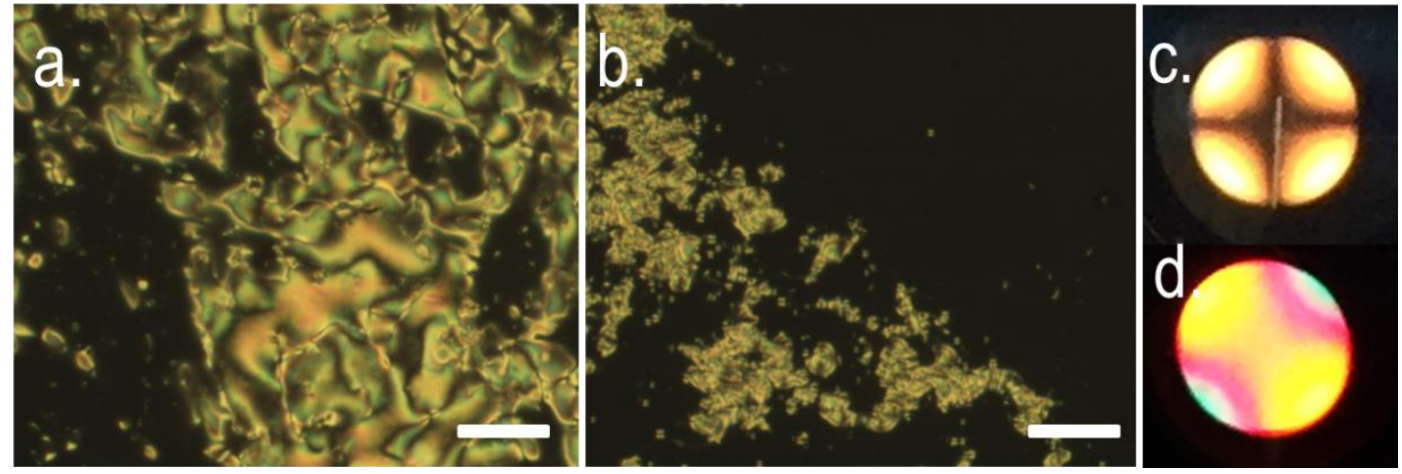

Figure SI-5: Photomicrographs $(x 100$, scale bar $100 \mu \mathrm{m})$ of the nematic phase $\left(\mathrm{a}, 70{ }^{\circ} \mathrm{C}\right)$ and the smectic A phase $\left(62{ }^{\circ} \mathrm{C}\right)$ of compound 5. (c) Conoscopic figure obtained in the smectic A phase demonstrating the phase to be uniaxial, insertion of a $1 / 4$ wave plate (d) demonstrates the phase to be optically positive. 


\section{Molecular dynamics simulations: methods and supplemental data}

Initial geometries for simulations were prepared by optimising the all-trans conformers of 8OCB and 9 at the B3LYP/6-31++G(d,p) level ${ }^{9,} 10$ using Gaussian 16 Rev A.03. ${ }^{11}$

Electrostatic potentials were then calculated at the $\mathrm{HF} / 6-31++\mathrm{G}(\mathrm{d}, \mathrm{p})$ level using Gaussian 16, before using AmberTools $19^{12}$ to generate a set of RESP ${ }^{13}$ atomic charges and a set of GAFF version 1.81 forcefield parameters. ${ }^{14}$ The forcefield parameters were then converted using ACPYPE ${ }^{15}$ and some forcefield parameters, namely the C-C-C-C torsional parameters and the non-bonded parameters for aromatic carbon atoms, were modified to those reported to give improved results for liquid crystal molecules. ${ }^{16}$ Fully atomistic molecular dynamics (MD) simulations were then performed with GROMACS 2019.3. ${ }^{17-23}$

All MD simulations were run with periodic boundary conditions using 2-fs steps, and all bonds were constrained at their equilibrium lengths using the LINCS algorithm. ${ }^{24} \mathrm{~A}$ van der Waals cutoff of $1.2 \mathrm{~nm}$ was used, and the Particle Mesh Ewald method ${ }^{25}$ was used for longrange electrostatic interactions with a cutoff of $1.2 \mathrm{~nm}$. Coordinates were written to trajectory files every $50 \mathrm{ps}$ for the main simulations. For the system preparation and equilibration steps, a velocity rescaling thermostat ${ }^{26}$ and Berendsen barostat ${ }^{27}$ were used, as appropriate; for the full simulations, a Nose-Hoover thermostat ${ }^{28,29}$ with a 1-ps time constant and a Parrinello-Rahman barostat ${ }^{30,31}$ with a 4-ps time constant were used. Dispersion correction was used for energy and pressure, and simulation trajectories were visualised in VMD $1.9 .4 .^{32}$

Initial simulation boxes were prepared by arranging molecules onto a regular $3 \mathrm{D}$ grid at a spacing corresponding to a gas-phase density $\left(<20 \mathrm{~kg} \mathrm{~m}^{-3}\right)$, and doing a simulation run to allow the system to randomise, before it was compressed to a liquid-phase density (ca. $1,000 \mathrm{~kg} \mathrm{~m}^{-3}$ ).

In order to estimate a clearing point in these MD simulations of $80 C B$ and 9 , a series of small simulations of $6 \times 6 \times 6=216$ molecules were performed. Each system was allowed to randomise for $40 \mathrm{ps}$ at low density at $298 \mathrm{~K}$ with no pressure coupling (final $P_{2}=0.1$ ), and then it was compressed rapidly at a nominal pressure of 50,000 bar until a liquid-like density was reached. The condensed, randomised phase was allowed to stabilise at 1 bar, before equilibrating at $353 \mathrm{~K}(8 \mathrm{OCB})$ or $358 \mathrm{~K}(9)$. A 500 -ns simulation was then run, during which each system formed a fairly stable smectic $A$ phase. Subsequently, 100-ns simulations were run from the final coordinates at a range of temperatures at ca. $10 \mathrm{~K}$ intervals both higher and lower than those at which the 500-ns run had been performed, and with isotropic pressure coupling at 1 bar. The orientational order parameters $\left(P_{2}\right)$ determined as a function of temperature $(T)$ were fitted to a Haller type equation, $P_{2}=\left[1-\left(T / T_{\mathrm{c}}\right)\right]^{\beta}$, where $T_{\mathrm{c}}$ gives an estimate of the clearing point of the system in the simulation and $\beta$ is an empirical parameter. The data and fits from these small simulations are shown in Figure SI-6, and gave estimated $T_{\mathrm{c}}$ values of ca. 395 and $400 \mathrm{~K}$ for $80 \mathrm{CB}$ and 9 , respectively, in these simulated systems. 

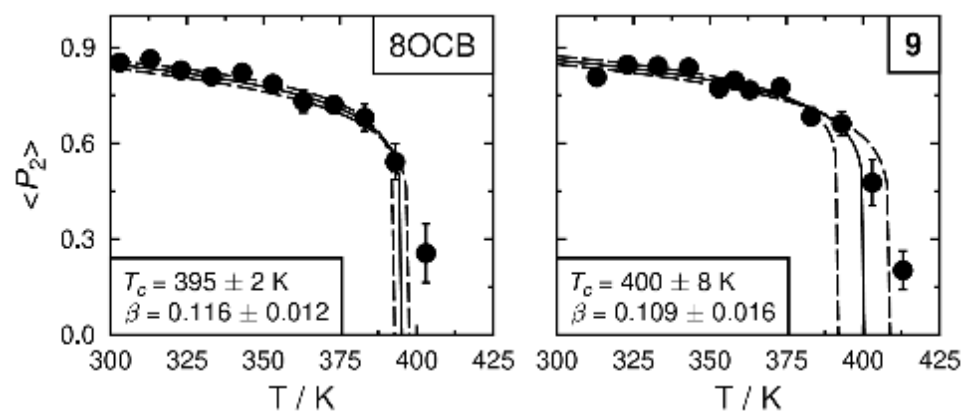

Figure SI-6. Orientational order parameters, $P_{2}$, averaged over 80-100 ns of the small MD simulations of $80 C B$ (left) and $\mathbf{9}$ (right) shown as markers, overlaid with fits (solid lines) and 95\% confidence limits shown by dashed lines. Error bars represent the standard deviation over the sampled time range of the MD simulation.

The larger simulations presented in the main text were performed at temperatures of 369 and $374 \mathrm{~K}$ for $80 \mathrm{CB}$ and $\mathrm{Cyc}-5 \mathrm{OCB}$, respectively, both corresponding to $\mathrm{T} / \mathrm{T}_{\mathrm{c}} \approx 0.934$, which was chosen to be in the experimental smectic $A$ range for $80 \mathrm{CB}$. Each of the larger runs was prepared as a low-density $3 \mathrm{D}$ grid of $12 \times 12 \times 10=1440$ molecules in an approximately cubic simulation box. The initial, ordered system was simulated for $70 \mathrm{ps}$ at a nominal pressure of 10 bar to allow the system to randomise (final $P_{2}=0.04$ ), and it was then compressed at a nominal pressure of 50,000 bar until a liquid-like density was reached. The system was then allowed to stabilise at 1 bar and the desired simulation temperature before running the final simulations. These simulations used anisotropic pressure coupling to allow the simulation box to change aspect ratio as the simulation progressed, such that the phase formed was not biased by a simulation box with a fixed aspect ratio.

Second-rank orientational order parameters, $P_{2}$, were calculated for each trajectory frame as $-2 \times$ the middle eigenvalue of the ordering tensor, $Q_{\alpha \beta}$, defined by Equation 1, where $N$ is the number of molecules, $j$ is the molecule number in the simulation, $\alpha$ and $\beta$ represent the Cartesian $\mathrm{x}, \mathrm{y}$ and $\mathrm{z}$ axes, $\delta$ is the Kronecker delta, and $a$ is the component of the principal molecular axis vector defined in the text. The director at each frame was defined as the eigenvector associated with the largest eigenvalue of the ordering tensor.

$$
Q_{\alpha \beta}=\frac{1}{N} \sum_{j=1}^{N} \frac{3 a_{j \alpha} a_{j \beta}-\delta_{\alpha \beta}}{2}
$$

The overall layer-normal vector was determined using a set of $N$ local layer-normal vectors determined using a suitable reference atom in each molecule, as identified in the main text. The local layer-normal vector of each molecule was determined by combining the reference atom position with those of the equivalent reference atoms in surrounding molecules that were within a cutoff distance of $1 \mathrm{~nm}$, fitting a plane through the set of reference atoms, and then the local layer-normal vector is a normal vector to that plane. The overall layer-normal vector was then determined for each trajectory frame as the eigenvector associated with the largest eigenvalue of an ordering tensor equivalent to Equation 1 but assembled from the set of local layer-normal vectors determined for that frame. 
The translational order parameter, $\mathrm{T}$, was then determined using the distribution of a suitable reference atom within the molecules along the overall layer-normal vector using Equation $2,{ }^{33}$ where $z$ is the position of a reference atom projected onto the overall layer-normal vector, $d$ is the layer spacing, which is optimised to give the highest value of $r$ for each trajectory frame, $L$ is the length of the box used in the analysis, and the angular brackets denote an ensemble average for that frame.

$$
\tau=\sqrt{\left[\left\langle\cos \left(\frac{2 \pi z}{d}\right)\right\rangle-\frac{d}{2 \pi L} \sin \left(\frac{2 \pi L}{d}\right)\right]^{2}+\left\langle\sin \left(\frac{2 \pi z}{d}\right)\right\rangle^{2}}
$$

For the large simulations presented in the main text, the angle, $\theta_{\mathbf{n k}}$, between the director, $\mathbf{n}$, and the layer normal vector, $\mathbf{k}$, was determined for each frame. Normalised orientational distribution functions for this angle, $f\left(\theta_{\mathrm{nk}}\right)$, were calculated by dividing the populations of these angles by $\sin \left(\theta_{\mathrm{nk}}\right)$, and are shown in Figure SI-7. The orientational distribution functions for $8 \mathrm{OCB}$ and 9 have their highest values at $<2^{\circ}$, indicating that the director tends to align with the layer normal in both simulations, corresponding to smectic A phases, whereas smectic $C$ phases would give a maximum significantly greater than $0^{\circ}$. The orientational distribution function is narrower for 9 than for $8 \mathrm{OCB}$, consistent with a more ordered phase.

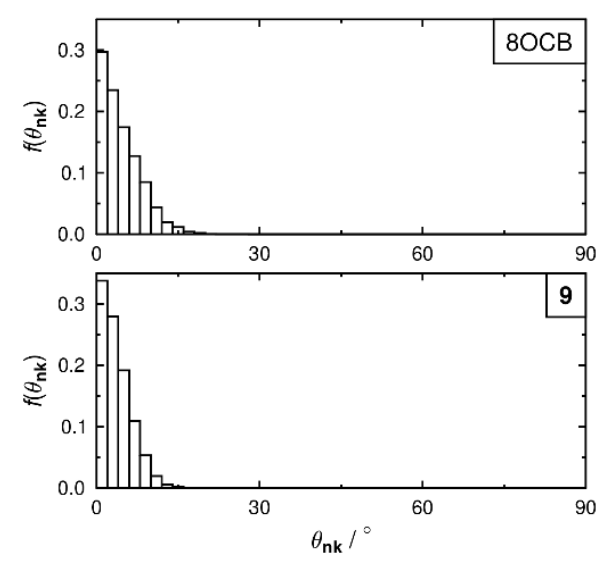

Figure SI-7. Orientational distribution functions, $f\left(\theta_{\mathrm{nk}}\right)$, determined for $8 \mathrm{OCB}$ (top) and 9 (bottom) from the MD simulations, averaged over 60-200 ns and 200-1000 ns, respectively, using $2^{\circ}$ binwidths.

The radial distribution function, $g(r)$ (Equation 3 ) reports on the relative probability of distances, $r_{i j}$, between a reference point on molecule $i$ and the equivalent point on molecule $j, \rho_{N}$ is the average number density of the system, and $\delta$ is the Dirac Delta function. Orientational correlation functions $G_{1}(r)$ and $G_{2}(r)$, Equations 4 and 5, respectively, report on the relative orientations between pairs of molecules, ${ }^{32}$ where $\theta_{i j}$ is the angle between a reference vector on molecule $i$ and the equivalent vector on another molecule, $j$. In this study, $g(r), G_{1}(r)$, and $G_{2}(r)$ were determined using vectors defined between the carbon atoms at the 4 and 4 ' positions of the biphenyl moieties, and distances, $r_{i j}$, were determined between the centre points of these two vectors. 


$$
\begin{gathered}
g(r)=\frac{1}{4 p r^{2} r_{N}}\left\langle d\left(r-r_{i j}\right)\right\rangle_{i j} \\
G_{1}(r)=\frac{\left\langle d\left(r-r_{i j}\right) \cos q_{i j}\right\rangle_{i j}}{\left\langle d\left(r-r_{i j}\right)\right\rangle_{i j}} \\
G_{2}(r)=\frac{\left\langle d\left(r-r_{i j}\right) P_{2}\left(\cos q_{i j}\right)\right\rangle_{i j}}{\left\langle d\left(r-r_{i j}\right)\right\rangle_{i j}}
\end{gathered}
$$

\section{Supplementary XRD data}

\subsection{Structure Determination by Single Crystal XRD}

Diffraction data were collected at $110 \mathrm{~K}$ on an Oxford Diffraction SuperNova diffractometer with Cu-K $\mathrm{K}_{\alpha}$ radiation $(\lambda=1.54184 \AA$ ) using an EOS CCD camera. The crystal was cooled with an Oxford Instruments Cryojet. Diffractometer control, data collection, initial unit cell determination, frame integration and unit-cell refinement was carried out with "Crysalis". ${ }^{35}$ Face-indexed absorption corrections were applied using spherical harmonics, implemented in SCALE3 ABSPACK scaling algorithm. ${ }^{36}$ OLEX2 ${ }^{37}$ was used for overall structure solution, refinement and preparation of computer graphics and publication data. Within OLEX2, the algorithm used for structure solution was ShelXT ${ }^{38}$ using intrinsic phasing. Refinement by fullmatrix least-squares used the SHELXL ${ }^{39}$ algorithm within OLEX2. ${ }^{37}$ All non-hydrogen atoms were refined anisotropically. Hydrogen atoms were placed using a "riding model" and included in the refinement at calculated positions.

\subsection{XRD Data for Compound 1}

Single crystals of $\mathrm{C}_{19} \mathrm{H}_{19} \mathrm{NO}$ (compound 1 ) were obtained by diffusion of ethanol and water into a DCM solution of $\mathbf{1}$.

\section{Crystal structure determination of 1}

Crystal Data for $\mathrm{C}_{19} \mathrm{H}_{19} \mathrm{NO}(M=277.35 \mathrm{~g} / \mathrm{mol})$ : triclinic, space group P-1 (no. 2), $a=$ 5.4374(3) $\AA, \quad b=10.4374(4) \AA, \quad c=13.6579(6) \AA, \quad \alpha=104.161(4)^{\circ}, \quad \beta=92.138(4)^{\circ}, \quad V=$ 95.945(4) $)^{\circ}, \quad V=745.94(6) \AA^{3}, Z=2, \quad T=110.05(10) \mathrm{K}, \mu(\mathrm{CuK \alpha})=0.589 \mathrm{~mm}^{-1}$, Dcalc $=$ $1.235 \mathrm{~g} / \mathrm{cm}^{3}, 13771$ reflections measured $\left(8.798^{\circ} \leq 2 \Theta \leq 142.356^{\circ}\right), 2867$ unique $\left(R_{\text {int }}=\right.$ $\left.0.0343, R_{\text {sigma }}=0.0251\right)$ which were used in all calculations. The final $R_{1}$ was $0.0410(\mathrm{I}>2 \sigma(\mathrm{I}))$ and $w R_{2}$ was 0.1119 (all data).

\subsection{XRD Data for Compound 2}

Single crystals of $\mathrm{C}_{20} \mathrm{H}_{21} \mathrm{NO}$ (compound 2) were obtained by slow evaporation of an ethanol solution. 


\section{Crystal structure determination of 2}

Crystal Data for $\mathrm{C}_{20} \mathrm{H}_{21} \mathrm{NO}(M=291.38 \mathrm{~g} / \mathrm{mol})$ : triclinic, space group P-1 (no. 2), $a=$ 5.6557(4) $\AA, \quad b=10.2172(9) \AA, \quad c=14.8788(10) \AA, \alpha=70.217(7)^{\circ}, \quad \beta=81.954(6)^{\circ}, \quad \gamma=$ $88.731(6)^{\circ}, \quad V=800.78(11) \AA^{3}, Z=2, T=110.05(10) \mathrm{K}, \mu(\mathrm{CuKa})=0.572 \mathrm{~mm}^{-1}$, Dcalc $=$ $1.208 \mathrm{~g} / \mathrm{cm}^{3}, 4627$ reflections measured $\left(9.202^{\circ} \leq 2 \Theta \leq 134.158^{\circ}\right), 2832$ unique $\left(R_{\text {int }}=0.0217\right.$, $\left.\mathrm{R}_{\text {sigma }}=0.0343\right)$ which were used in all calculations. The final $R_{1}$ was $0.0456(\mathrm{I}>2 \sigma(\mathrm{I}))$ and $w R_{2}$ was 0.1288 (all data).

\subsection{XRD Data for Compound 3}

Single crystals of $\mathrm{C}_{21} \mathrm{H}_{23} \mathrm{NO}$ (compound 3) were obtained by diffusion of ethanol into a DCM solution of 3.

\section{Crystal structure determination of 3}

Crystal Data for $\mathrm{C}_{21} \mathrm{H}_{23} \mathrm{NO}(M=305.40 \mathrm{~g} / \mathrm{mol})$ : monoclinic, space group $\mathrm{P} 2 / \mathrm{h}$ (no. 14), $a=$ 12.1243(2) $\AA, b=6.58920(10) \AA, c=21.5514(3) \AA, \beta=105.406(2)^{\circ}, V=1659.86(5) \AA^{3}, Z=$ $4, T=110.05(10) \mathrm{K}, \mu(\mathrm{CuK \alpha})=0.574 \mathrm{~mm}^{-1}$, Dcalc $=1.222 \mathrm{~g} / \mathrm{cm}^{3}, 11210$ reflections measured $\left(7.63^{\circ} \leq 2 \Theta \leq 134.134^{\circ}\right), 2962$ unique $\left(R_{\text {int }}=0.0222, R_{\text {sigma }}=0.0164\right)$ which were used in all calculations. The final $R_{1}$ was $0.0397(\mathrm{I}>2 \sigma(\mathrm{I}))$ and $w R_{2}$ was 0.1093 (all data).

\subsection{XRD Data for Compound 4}

Single crystals of $\mathrm{C}_{22} \mathrm{H}_{25} \mathrm{NO}$ (compound 4) were obtained by slow evaporation of an ethanol solution of 4 .

\section{Crystal structure determination of 4}

Crystal Data for $\mathrm{C}_{22} \mathrm{H}_{25} \mathrm{NO}(M=319.43 \mathrm{~g} / \mathrm{mol})$ : triclinic, space group P-1 (no. 2), $a=$ 7.0753(4) $\AA, \quad b=9.7137(5) \AA, \quad c=13.3506(8) \AA, \quad \alpha=78.906(5)^{\circ}, \quad \beta=83.156(5)^{\circ}, \quad \gamma=$ $82.858(5)^{\circ}, \quad V=889.13(9) \AA^{3}, Z=2, \quad T=110.05(10) \mathrm{K}, \mu(\mathrm{CuK \alpha})=0.556 \mathrm{~mm}^{-1}$, Dcalc $=$ $1.193 \mathrm{~g} / \mathrm{cm}^{3}, 5477$ reflections measured $\left(6.78^{\circ} \leq 2 \Theta \leq 134.158^{\circ}\right), 3180$ unique $\left(R_{\text {int }}=0.0189\right.$, $\left.\mathrm{R}_{\text {sigma }}=0.0285\right)$ which were used in all calculations. The final $R_{1}$ was $0.0406(I>2 \sigma(I))$ and $w R_{2}$ was 0.1138 (all data).

\subsection{XRD Data for Compound 5}

Single crystals of $\mathrm{C}_{23} \mathrm{H}_{27} \mathrm{NO}$ (compound 5) were obtained by diffusion of ethanol into a DCM solution of 5 .

\section{Crystal structure determination of compound 5}

Crystal Data for $\mathrm{C}_{23} \mathrm{H}_{27} \mathrm{NO}(M=333.45 \mathrm{~g} / \mathrm{mol})$ : triclinic, space group P-1 (no. 2), $a=$ $7.4340(6) \AA, \quad b=9.3359(6) \AA, \quad c=13.7657(9) \AA, \quad \alpha=80.118(6)^{\circ}, \quad \beta=82.186(6)^{\circ}, \quad \gamma=$ $81.713(6)^{\circ}, V=925.30(12) \AA^{3}, Z=2, T=110.05(10) \mathrm{K}, \mu(\mathrm{CuK \alpha})=0.554 \mathrm{~mm}^{-1}$, Dcalc $=$ 
$1.197 \mathrm{~g} / \mathrm{cm}^{3}, 5581$ reflections measured $\left(9.69^{\circ} \leq 2 \Theta \leq 134.16^{\circ}\right), 3303$ unique $\left(R_{\text {int }}=0.0246\right.$, $\left.R_{\text {sigma }}=0.0400\right)$ which were used in all calculations. The final $R_{1}$ was $0.0480(I>2 \sigma(I))$ and $w R_{2}$ was 0.1367 (all data). 


\subsection{Supplemental Single Crystal X-ray Diffraction Data}

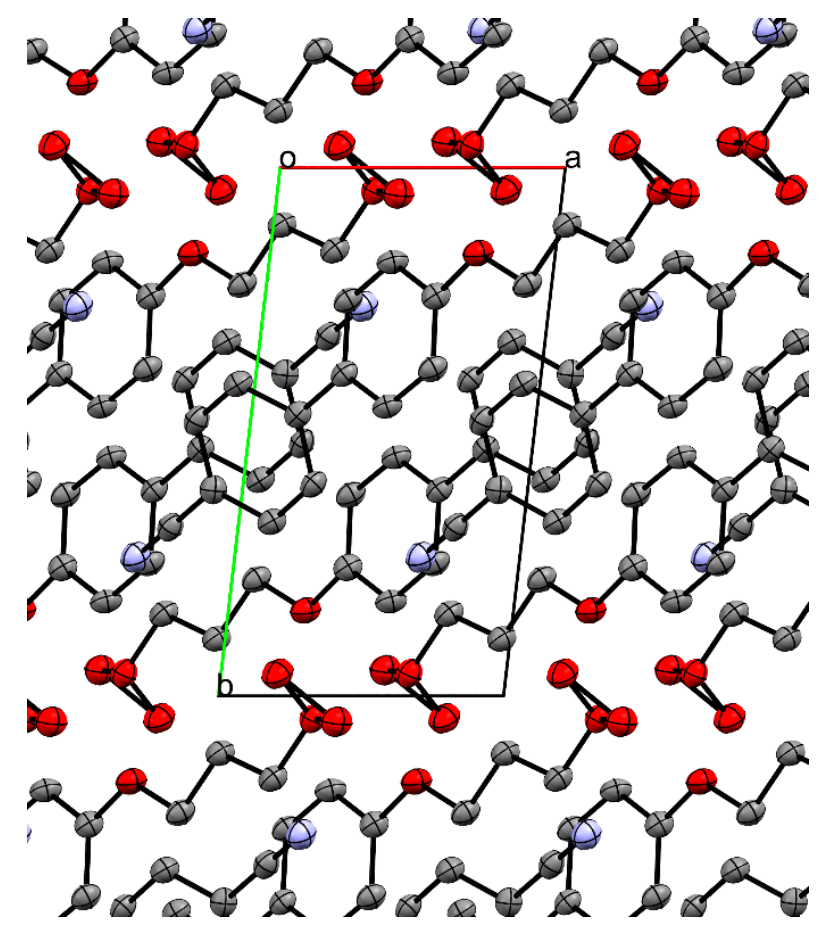

Figure SI-8: Packing in the crystalline state of compound 1 as determined by single crystal XRD (P-1(2) space group). Hydrogen atoms are excluded and the carbon atoms of the cyclopropyl ring are coloured red, both for clarity 


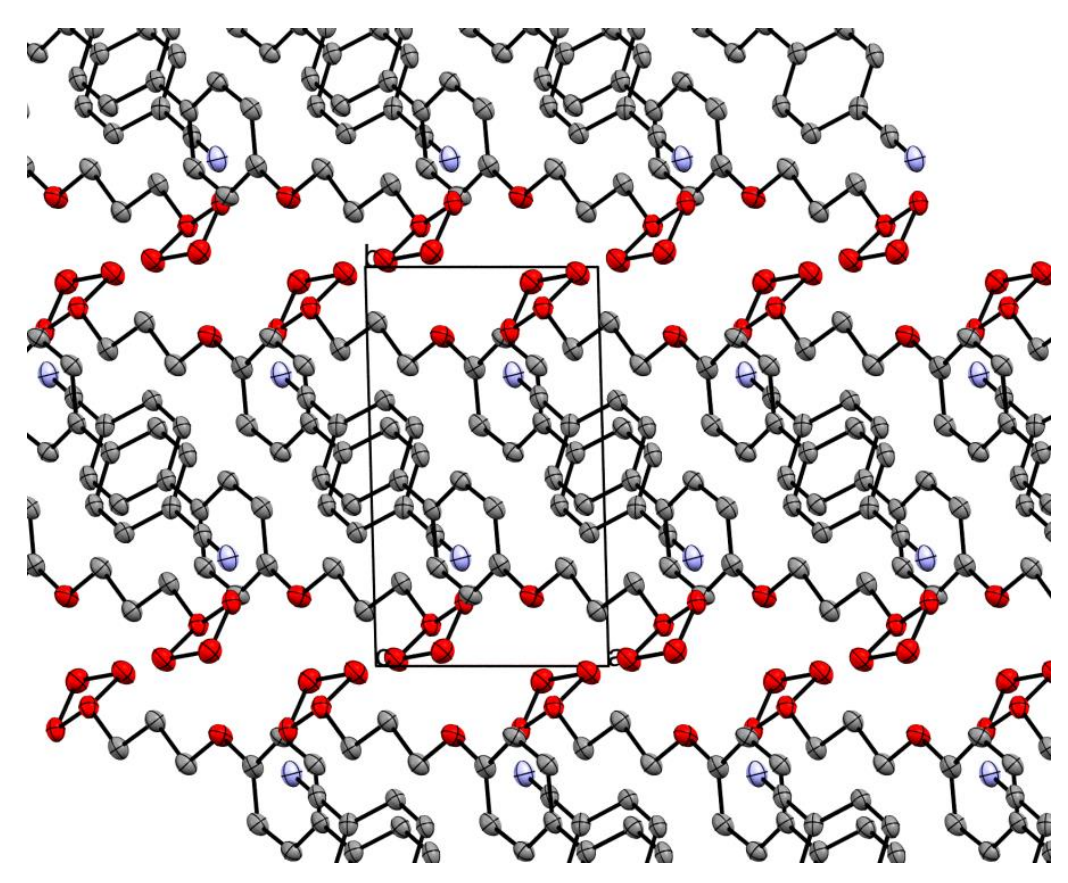

Figure SI-9: Packing in the crystalline state of compound 2 as determined by single crystal XRD (P-1 space group). Hydrogen atoms are excluded and the carbon atoms of the cyclobutyl ring are coloured red, both for clarity

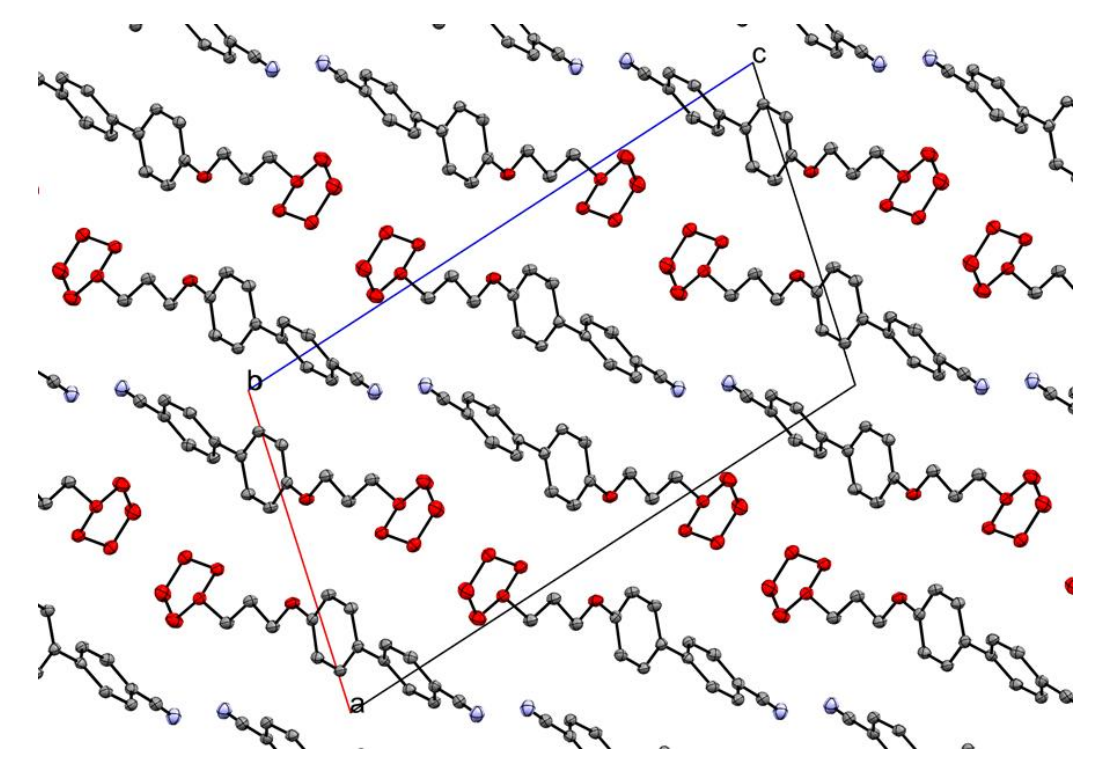

Figure SI-10: Packing in the crystalline state of compound $\mathbf{3}$ as determined by single crystal XRD (p21/n space group). Hydrogen atoms are excluded and the carbon atoms of the cyclopentyl ring are coloured red, both for clarity 


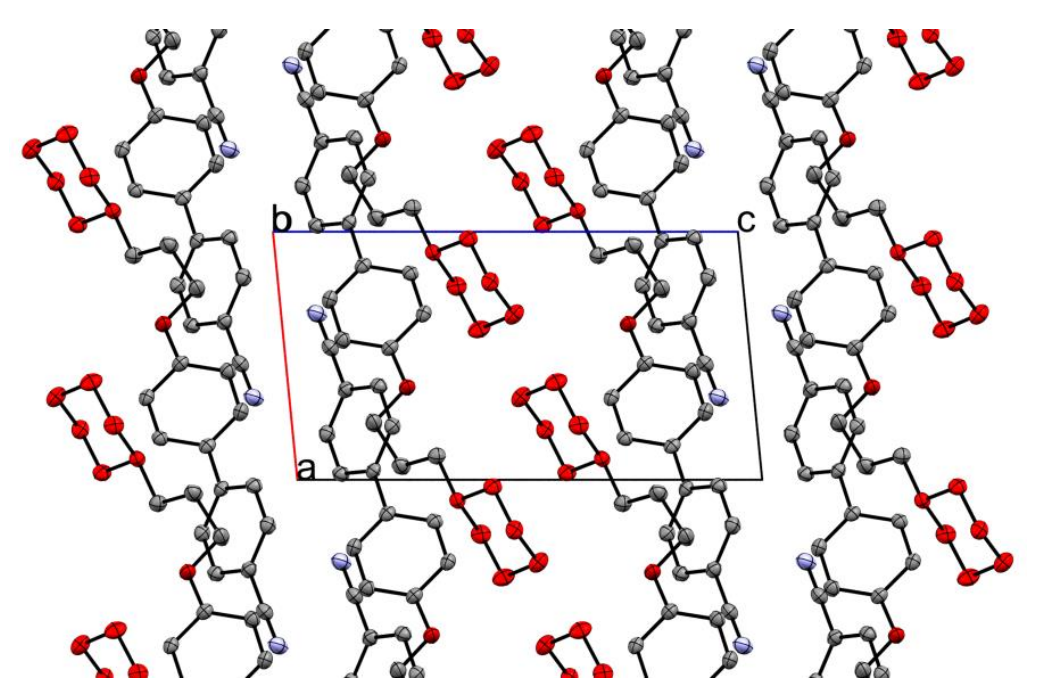

Figure SI-11: Packing in the crystalline state of compound $\mathbf{4}$ as determined by single crystal $\mathrm{XRD}(\mathrm{P} \overline{1}$ space group). Hydrogen atoms are excluded and the carbon atoms of the cyclohexyl ring are coloured red, both for clarity

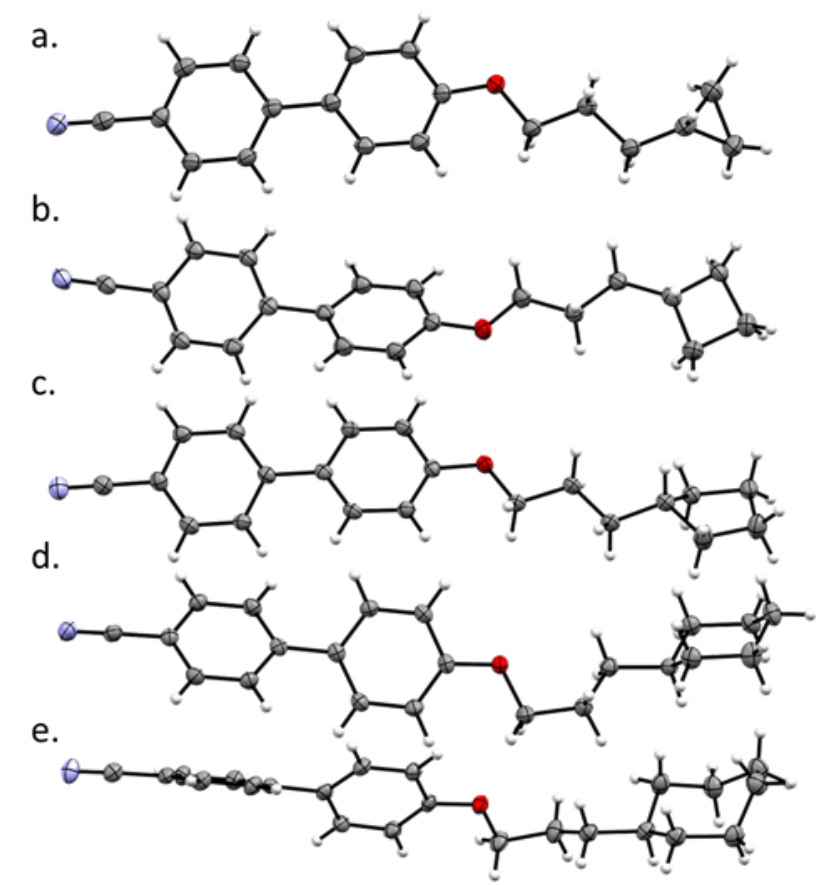

Figure SI-12: Thermal ellipsoid models (50\% probability level) of compounds 1 (a, space group P-1), 2 (b, space group P-1) 3 (c, space group P2 $1 / n$ ), 4 (d, space group $\mathrm{P}-1)$ and 5 (e, space group $\mathrm{P}-1$ ) obtained by single crystal XRD. 


\subsection{Discussion of Single Crystal X-ray Diffraction Data}

Cyclopropyl and cyclobutyl rings are effectively rigid, whereas larger rings can adopt a number of conformers ${ }^{34}$ with the lowest energy forms being half-boat (3), boat (4) and twist-boat (5) for cyclopentyl, cyclohexyl and cycloheptyl, respectively. To determine the conformation of the terminal rings we grew single crystals of compounds $\mathbf{1}$ - $\mathbf{5}$ suitable for structure determination by X-ray diffraction. For compounds $\mathbf{4}$ and $\mathbf{5}$ the end-to-end distances in the solid state $\mathbf{4}=$ $17.924(2) \AA, 5=18.329(3) \AA$ ) were found to be slightly smaller than those obtained from DFT calculations ( $\mathbf{4}=18.73 \AA, 5=18.78 \AA$ ) due to the presence of a single gauche torsion in the spacer (Figure $2 b, 2 c$ ). For $\mathbf{1}-\mathbf{3}$ the spacer was found to be in its all trans conformer and so the molecular length $(16.941(2), 17.627(3)$ and $18.140(2) \AA$ respectively) from XRD is comparable to that obtained by DFT calculations ( $16.99 \AA, 17.62 \AA$ and $18.10 \AA$ respectively).

\section{References}

1. M. S. Lowry, J. I. Goldsmith, J. D. Slinker, R. Rohl, R. A. Pascal, G. G. Malliaras and S. Bernhard, Chem Mater, 2005, 17, 5712-5719.

2. C. P. Johnston, R. T. Smith, S. Allmendinger and D. W. C. MacMillan, Nature, 2016, 536, 322-325.

3. T. Qin, J. Cornella, C. Li, L. R. Malins, J. T. Edwards, S. Kawamura, B. D. Maxwell, M. D. Eastgate and P. S. Baran, Science, 2016, 352, 801-805.

4. R. J. Mandle and J. W. Goodby, Liq Cryst, 2017, 44, 656-665.

5. L. J. Perez, W. L. Ng, P. Marano, K. Brook, B. L. Bassler and M. F. Semmelhack, J Med Chem, 2012, 55, 9669-9681.

6. Y. F. Tian, A. B. Ling, R. Fang, R. X. Tan and Z. Q. Liu, Green Chem, 2018, 20, 3432-3435.

7. M. J. Frisch, G. W. Trucks, H. B. Schlegel, G. E. Scuseria, M. A. Robb, J. R. Cheeseman, G. Scalmani, V. Barone, B. Mennucci, G. A. Petersson, H. Nakatsuji, M. Caricato, X. Li, H. P. Hratchian, A. F. Izmaylov, J. Bloino, G. Zheng, J. L. Sonnenberg, M. Hada, M. Ehara, K. Toyota, R. Fukuda, J. Hasegawa, M. Ishida, T. Nakajima, Y. Honda, O. Kitao, H. Nakai, T. Vreven, J. A. Montgomery Jr., J. E. Peralta, F. Ogliaro, M. J. Bearpark, J. Heyd, E. N. Brothers, K. N. Kudin, V. N. Staroverov, R. Kobayashi, J. Normand, K. Raghavachari, A. P. Rendell, J. C. Burant, S. S. lyengar, J. Tomasi, M. Cossi, N. Rega, N. J. Millam, M. Klene, J. E. Knox, J. B. Cross, V. Bakken, C. Adamo, J. Jaramillo, R. Gomperts, R. E. Stratmann, O. Yazyev, A. J. Austin, R. Cammi, C. Pomelli, J. W. Ochterski, R. L. Martin, K. Morokuma, V. G. Zakrzewski, G. A. Voth, P. Salvador, J. J. Dannenberg, S. Dapprich, A. D. Daniels, Ö. Farkas, J. B. Foresman, J. V. Ortiz, J. Cioslowski and D. J. Fox, Gaussian 09 revison E01, 2009.

8. K. Itoh, M. Kori, Y. Inada, K. Nishikawa, Y. Kawamatsu and H. Sugihara, Chem Pharm Bull (Tokyo), 1986, 34, 1128-1147.

9. A. D. Becke, J. Chem. Phys., 1993, 98, 5648-5652.

10. C. T. Lee, W. T. Yang and R. G. Parr, Phys. Rev. B, 1988, 37, 785-789.

11. M. J. Frisch, G. W. Trucks, H. B. Schlegel, G. E. Scuseria, M. A. Robb, J. R. Cheeseman, G. Scalmani, V. Barone, G. A. Petersson, H. Nakatsuji, X. Li, M. Caricato, A. V. Marenich, J. Bloino, B. G. Janesko, R. Gomperts, B. Mennucci, H. P. Hratchian, J. V. Ortiz, A. F. Izmaylov, J. L. Sonnenberg, Williams, F. Ding, F. Lipparini, F. Egidi, J. Goings, B. Peng, A. Petrone, T. Henderson, D. Ranasinghe, V. 
G. Zakrzewski, J. Gao, N. Rega, G. Zheng, W. Liang, M. Hada, M. Ehara, K. Toyota, R. Fukuda, J. Hasegawa, M. Ishida, T. Nakajima, Y. Honda, O. Kitao, H. Nakai, T. Vreven, K. Throssell, J. A. Montgomery Jr., J. E. Peralta, F. Ogliaro, M. J. Bearpark, J. J. Heyd, E. N. Brothers, K. N. Kudin, V. N. Staroverov, T. A. Keith, R. Kobayashi, J. Normand, K. Raghavachari, A. P. Rendell, J. C. Burant, S. S. Iyengar, J. Tomasi, M. Cossi, J. M. Millam, M. Klene, C. Adamo, R. Cammi, J. W. Ochterski, R. L. Martin, K. Morokuma, O. Farkas, J. B. Foresman and D. J. Fox, Gaussian G16 revision A03, 2016.

12. D.A. Case, I. Y. Ben-Shalom S.R. Brozell, D.S. Cerutti, T.E. Cheatham, III, V.W.D. Cruzeiro, T.A. Darden,; R.E. Duke, D. G., G. Giambasu, T. Giese, M.K. Gilson, H. Gohlke, A.W. Goetz, D. Greene, R Harris,; N. Homeyer, Y. H., S. Izadi, A. Kovalenko, R. Krasny, T. Kurtzman, T.S. Lee, S. LeGrand, P. Li, C. Lin,; J. Liu, T. L., R. Luo, V. Man, D.J. Mermelstein, K.M. Merz, Y. Miao, G. Monard, C. Nguyen, H.; Nguyen, A. O., F. Pan, R. Qi, D.R. Roe, A. Roitberg, C. Sagui, S. Schott-Verdugo, J. Shen, C.L.; Simmerling, J. S., J. Swails, R.C. Walker, J. Wang, H. Wei, L. Wilson, R.M. Wolf, X. Wu, L. Xiao, Y.; Xiong, D. M. Y. a. P. A. K., AMBER 2019. University of California: San Francisco, 2019.

13. C. I. Bayly, P. Cieplak, W. Cornell and P. A. Kollman, J. Phys. Chem., 1993, 97, 10269-10280.

14. J. Wang, R. M. Wolf, J. W. Caldwell, P. A. Kollman and D. A. Case, J Comput Chem, 2004, 25, 1157-1174.

15. A. W. Sousa da Silva and W. F. Vranken, BMC Research Notes, 2012, 5, 367-367.

16. N. J. Boyd and M. R. Wilson, Phys Chem Chem Phys, 2015, 17, 24851-24865.

17. M. J. Abraham, T. Murtola, R. Schulz, S. Páll, J. C. Smith, B. Hess and E. Lindahl, SoftwareX, 2015, 1-2, 19-25.

18. S. Páll, M. J. Abraham, C. Kutzner, B. Hess and E. Lindahl, in Solving Software Challenges for Exascale: International Conference on Exascale Applications and Software, EASC 2014, Stockholm, Sweden, April 2-3, 2014, Revised Selected Papers, eds. S. Markidis and E. Laure, Springer International Publishing, Cham, 2015, DOI: 10.1007/978-3-319-15976-8_1, pp. 3-27.

19. S. Pronk, S. Páll, R. Schulz, P. Larsson, P. Bjelkmar, R. Apostolov, M. R. Shirts, J. C. Smith, P. M. Kasson, D. van der Spoel, B. Hess and E. Lindahl, Bioinformatics, 2013, 29, 845-854.

20. B. Hess, C. Kutzner, D. van der Spoel and E. Lindahl, J. Chem. Theor. Comput., 2008, 4, 435-447.

21. D. Van der Spoel, E. Lindahl, B. Hess, G. Groenhof, A. E. Mark and H. J. C. Berendsen, J. Comput. Chem., 2005, 26, 1701-1718.

22. E. Lindahl, B. Hess and D. van der Spoel, J. Mol. Model., 2001, 7, 306-317.

23. H. J. C. Berendsen, D. Vanderspoel and R. Vandrunen, Comput. Phys. Commun., 1995, 91, 43-56.

24. B. Hess, H. Bekker, H. J. C. Berendsen and J. G. E. M. Fraaije, J Comput Chem, 1997, 18, 1463-1472.

25. U. Essmann, L. Perera, M. L. Berkowitz, T. Darden, H. Lee and L. G. Pedersen, J. Chem. Phys., 1995, 103, 8577-8593.

26. G. Bussi, D. Donadio and M. Parrinello, J. Chem. Phys., 2007, 126, 014101.

27. H. J. C. Berendsen, J. P. M. Postma, W. F. van Gunsteren, A. DiNola and J. R. Haak, J. Chem. Phys., 1984, 81, 3684-3690.

28. S. Nosé, Mol Phys, 1984, 52, 255-268.

29. W. G. Hoover, Phys Rev A, 1985, 31, 1695-1697.

30. M. Parrinello and A. Rahman, J Appl Phys, 1981, 52, 7182-7190.

31. S. Nosé and M. L. Klein, Mol Phys, 1983, 50, 1055-1076.

32. W. Humphrey, A. Dalke and K. Schulten, J. Mol. Graph., 1996, 14, 33-38.

33. M. F. Palermo, A. Pizzirusso, L. Muccioli and C. Zannoni, J. Chem. Phys., 2013, 138, 204901. 
34. D. F. Bocian, H. M. Pickett, T. C. Rounds and H. L. Strauss, J Am Chem Soc, 1975, 97, 687-695.

35. CrysAlisPro, Oxford Diffraction Ltd. Version 1.171.34.41

36. Empirical absorption correction using spherical harmonics, implemented in SCALE3 ABSPACK scaling algorithm within CrysAlisPro software, Oxford Diffraction Ltd. Version 1.171.34.40

37. “Olex2” crystallography software, J. Appl. Cryst., 2009, 42, 339-341.

38. SHELXT - Integrated space-group and crystal-structure determination, G. M. Sheldrick, Acta Cryst. 2015, A71, 3-8

39. "SHELXL-97" - program for the Refinement of Crystal Structures, G.M. Sheldrick, Acta Cryst. 2008, A64, 112-122. 